\title{
New silverfish species (Zygentoma: Lepismatidae) from Barrow Island
}

\author{
Graeme B. Smith \\ Australian Museum, 6 College Street, Sydney, New South Wales 2010, Australia. \\ Federation University Australia, PO Box 663, Ballarat, Victoria 3353, Australia. \\ Email: le_gbsmith@optusnet.com.au
}

\begin{abstract}
Three new species of the subfamily Ctenolepismatinae (Qantelsella maculosa sp. nov., Q. aurantia sp. nov. and Acrotelsella transpectinata sp. nov.) and one of the subfamily Lepismatinae (Xenolepisma perexiguum sp. nov.) are described from Barrow Island. Keys are provided for the described species of Qantelsella Smith and Xenolepisma Mendes.
\end{abstract}

KEYWORDS: Thysanura, taxonomy, new species

\section{INTRODUCTION}

Smith (2013) reported on the diverse silverfish fauna of Barrow Island, collected by a team from Curtin University (Callan et al. 2011), in which he described just one of the species recorded (Heterolepisma parva). This paper describes a further four species, leaving most of the remaining Barrow Island Acrotelsella Silvestri, 1935 species undescribed until a wider revision of this large genus is possible.

\section{SPECIMEN SELECTION AND PREPARATION}

Silverfish were collected by Callen et al. 2011, from various locations on Barrow Island, mostly using pitfall traps, Winkler sack sampling of litter, suction sampling of low vegetation and some limited hand-sampling. For details of collection sites and collection methods see Callen et al. (2011). Where many examples of a morphospecies were available, a type series was selected from a few tubes containing mostly larger individuals. All specimens were initially stored in $100 \%$ ethanol and later transferred to $75-80 \%$ ethanol. All locality grid coordinates are quoted using the datum WGS84 (50).

Measurement data of whole specimens in alcohol and their dissection used the methods described in Smith (2013). The numbers of specimens measured varied with species ranging from just one to 25 depending on availability. Where available, at least one male and one female specimen of the selected type series (always including the holotype) were dissected and each mounted onto two microscope slides (one slide with head and thorax, the other with the abdomen). Types are deposited with the Western Australian Museum, 49 Kew Street, Welshpool, Western Australia 6106. Where sufficient material is available, representative specimens are also deposited with the Australian Museum, 6 College Street, Sydney, New South Wales 2010 (indicated under material examined for each species) while the remainder of the material will be sent to the Entomology Branch of the Department of Agriculture and Food, Western Australia, 3 Baron-Hay Court, South Perth 6151, Western Australia.

Specimens used for scanning electron microscopy were put through an ethanol dehydration series then critical point dried using a Leica EMCPD300. They were mounted on a pin or on a double-sided carbon tab stub and gold sputter-coated using an Emitech K550 Gold Sputter-coater. Specimens were imaged using the Zeiss EVO LS15 SEM with a Robinson backscatter detector.

Roman numerals are used to indicate abdominal segment number. In addition the following abbreviations are used: AMS: Australian Museum, Sydney; HW: head width (in millimetres); $\mathrm{H}+\mathrm{B}$ : head and body length (in millimetres); L/W: length to width (ratio); PI, PII, PIII: legs of prothorax, mesothorax and metathorax respectively; PIT: pitfall trap; SEM: scanning electron microscope; SUC: suction sample; WAM: Western Australian Museum; WSC: Winkler sack sample. The term macrochaetae refers to the larger stronger bristles (mostly pectinate in the Ctenolepismatinae and smooth but apically bifurcate in the Lepismatinae), setae refers to smaller thinner bristles (mostly simple), setulae to the very small, usually straight, setae associated with the combs and cilia to the curly thin hairs, often associated with the combs, setal collar or notal margins. Prosternum, mesosternum and metasternum are used for the sterna of the pro-, meso- and metathoracic segments.

In previous publications this author has used the term 'articles' for the 'segments' of the antennae, terminal filaments and ovipositor. There seems, 
however, to be a general consensus among Zygentoma workers that the term article should only be used for articulated non-metameric 'segments' which have their own intrinsic musculature (e.g. legs, pedicel, scape, palps) and therefore not appropriate for the flagellum, cerci and ovipositor. The flagellum of the Zygentoma demonstrates both proximal and intercalary growth (Larink, 1986), resulting in a complex arrangement of divisions and annuli each with its own setae and sensillae. In this paper, the term annulus will be used for each single unit, usually a widened region carrying a single rosette of setae (but occasionally with a smaller secondary rosette). An annulus may or may not be separated from the adjacent annuli by distinct sutures. Basal annuli are usually simple with a single rosette of setae and distinct trichobothria. More distally these annuli become longer and soon divide into two annuli, each with its own rosette of setae but the trichobothria are only found in the distal annulus. Adel (1984) referred to an annulus with trichobothria as a 'T-Glied' and Molero-Baltanás et al. (2000) as a 'T-joint'. Further divisions usually appear more distally, with three, four or more annuli, again with the trichobothria (-um) only in the most distal annulus. The group of annuli between the T-Glieder (including the distal T-Glied) has been referred to as an 'Intervall' (Adel, 1984), 'periodic unit' (Molero-Baltanás et al. 2000) or simply 'division' (e.g. Mendes 2012) although the term T-interval has also been used in correspondence. The terms interval and T-annulus will be used in this paper to indicate these periodic units and their distal annulus, recognising that in species of Qantelsella Smith, 2015 the trichobothria seem to have been replaced by alternate sensillae on the ultimate annulus in the more distal parts of the antennae. An interval may consist of just a single annulus in the basal part of the antennae or of several annuli in the distal regions. The first subdivision of the basal annuli or intervals generally show a much more distinct suture than seen with subsequent subdivisions, resulting in the interval consisting of two parts, each with one to several annuli. Molero-Baltanás et al. (2000) called each of the resulting two sections of annuli 'chains' and this has been followed by Mendes (2012). For the terminal filaments and ovipositor, the term division will be used for each 'segment' defined by a visible suture, albeit often faint.

\section{SYSTEMATICS}

\section{Family Lepismatidae Latreille 1802}

Lepismenae Latreille, 1802: 70 pro parte.

Lepismatidae Burmeister, 1838: 452 pro parte.

Subfamily Ctenolepismatinae Mendes 1991

Ctenolepismatinae Mendes, 1991: 11.
Qantelsella Smith, 2015

Qantelsella Smith, 2015: 68.

\section{TYPE SPECIES}

Qantelsella louisae Smith, 2015: 68, by original designation.

\section{Qantelsella maculosa sp. nov.}

urn:Isid:zoobank.org:act:4AACB02A-ECC5-4755-B9ECB2AAF5D93989

Figures 1-55

\section{MATERIAL EXAMINED}

\section{Holotype}

Australia: Western Australia: 우 (HW 1.00), Barrow Island, site GP2 (339462, 7699669), 15 March 2006, S. Callan, R. Graham, PIT (WAM E88546) on two slides.

\section{Paratypes}

Australia: Western Australia: juvenile $\bigcirc$ (HW 0.78), Barrow Island, site CC2 (337659, 7697280), 15 March 2006, S. Callan, R. Graham, PIT (WAM E88547) in ethanol; juvenile $q$ (HW 0.78), same data as previous (WAM E88548) in ethanol; $\widehat{\sigma}$ (HW 0.93), Barrow Island, site GPX (338920, 7699669), 25 September 2006, S. Callan, R. Graham, PIT (WAM E88549) on two slides; $\widehat{O}$ (HW 0.70), Barrow Island, site N27 (326266, 7691041), 6 May 2006, S. Callan, R. Graham, SUC (WAM E88550) in alcohol.

\section{Other material examined in detail but not included in types series:}

Australia: Western Australia: juvenile $\odot$ (HW 0.78), Barrow Island, site N10 (330643, 7696589), 1 May 2007, S. Callan, K. Edwards, SUC (AMS K261101, K261102) on two slides; juvenile (HW 0.44), same data as previous (WAM E89197); juvenile (HW 0.63) Barrow Island, site N10 (337659, 7697280), 1 May 2007, S. Callan, K. Edwards, WSC (AMS) used for scanning electron microscopy.

\section{DIAGNOSIS}

This species can easily be distinguished from the other known species of Qantelsella by the distinct projections of the frons over the base of the antennae, by presence of combs rather than groups of macrochaetae on the clypeus, by the very short trichobothria located very close to the margins of the nota and not associated with combs of macrochaetae, by the round and glabrous metasternum, by the lateral combs of the urotergites having only a single macrochaeta and by the absence of scales on the terminal filaments (see discussion on generic placement of this and the following species after the description of the next species). 


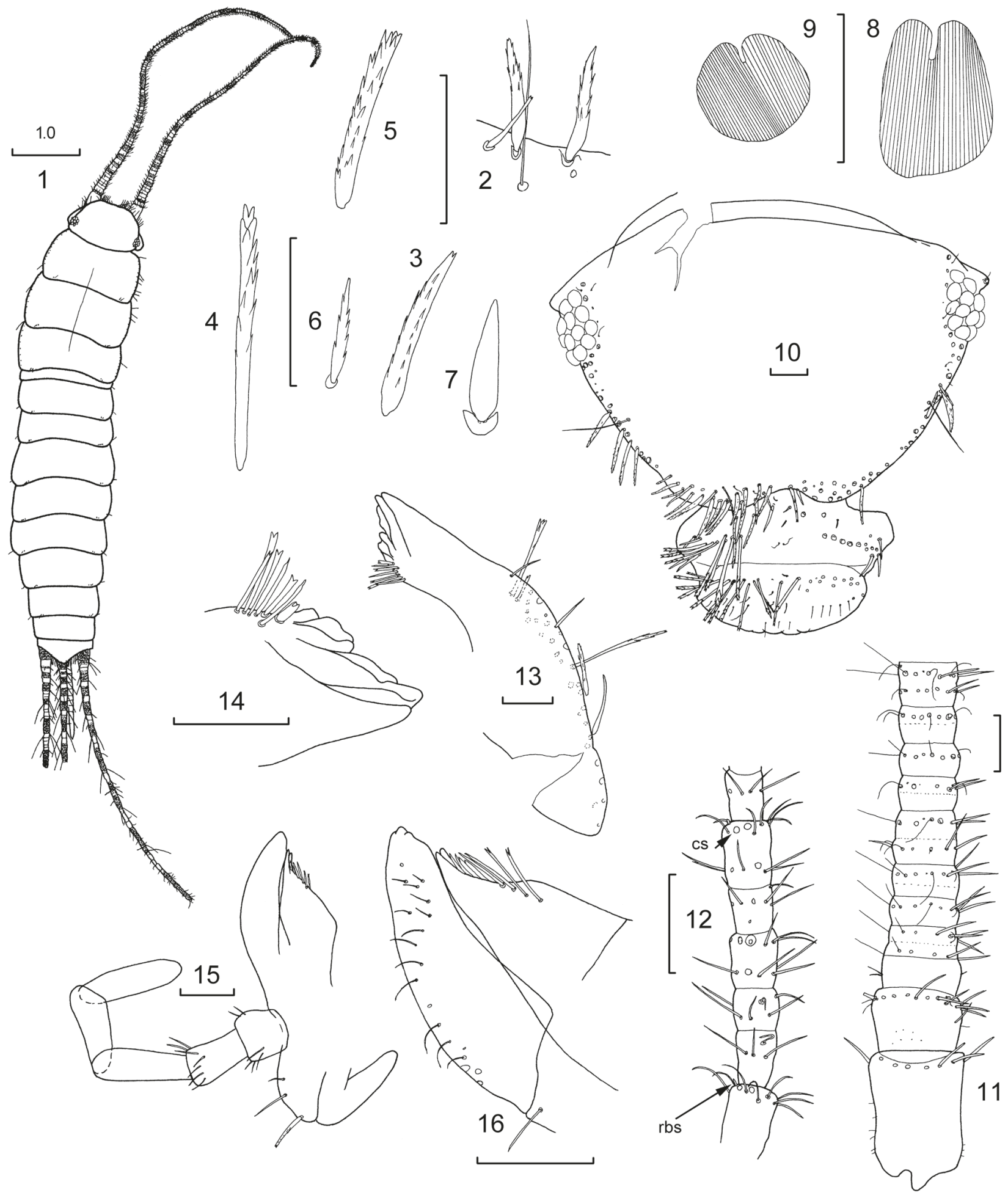

FIGURES 1-16 Qantelsella maculosa sp. nov., holotype female (WAM E88546) unless otherwise noted by specimen number: 1, habitus; 2, lateral macrochaetae and thin seta of head (K261101); 3, macrocheta from anterior margin of head; 4, macrochaeta from clypeus; 5 , macrochaeta from anterior corner of prothorax (K261101); 6, macrochaeta from notal collar of prothorax; 7, smooth macrochaeta from apex of tibia; 8; scale from pronotum; 9, scale from metanotum (K261101); 10, head; 11, antenna, scape, pedicel and basal intervals/annuli of flagellum; 12, idem, most distal surviving interval showing rod-like basiconic sensilla (rbs) and circular sensilla (cs); 13, mandible; 14, idem, enlargement of distal end; 15, maxilla; 16 , idem, enlargement of distal end of lacinia and galea. Scale bars $=0.1 \mathrm{~mm}$ unless otherwise indicated. 


\section{DESCRIPTION}

Appearance: Body fairly elongate with the thorax only slightly wider than abdominal segment I, the following abdominal segments about the same width until the sixth and only narrowing slightly towards the posterior end (Figure 1). Appearance when live unknown; in alcohol mottled brown with very distinct, darkly pigmented banding on the terminal filaments and antennae and dark patches on the legs. Dorsally covered with brown scales.

Body size: $\mathrm{H}+\mathrm{B}$ up to about $6.5 \mathrm{~mm}(+)$ (an estimation as abdomen somewhat distended in largest specimen and measured at $7.13 \mathrm{~mm}$ ), $4.6 \mathrm{~mm}($ đ); maximum head width $1.00 \mathrm{~mm}$; thorax: length up to $1.68 \mathrm{~mm}$ or 0.31 times $\mathrm{H}+\mathrm{B}$ (range $0.24-0.38$ ); width up to $1.43 \mathrm{~mm}$ being widest at the meso or metathorax, all nota about the same length; antennae probably incomplete in all specimens, maximum surviving length of antenna 4.75 mm or 0.73 times estimated $\mathrm{H}+\mathrm{B}$; terminal filaments quite long although broken in most specimens, maximum surviving length of cercus $5.2 \mathrm{~mm}$ or when complete 0.80-0.98 H+B; maximum length of intact median appendage $4.38 \mathrm{~mm}(1-1.2 \mathrm{H}+\mathrm{B})$.

Pigmentation: Often quite dark, especially on older larger specimens. Head without strong pigmentation dorsally but clypeus and labrum distinctly pigmented in larger specimens. Pedicel and scape with pigment; flagellum with bands of dark pigment from about the seventh interval with light and dark bands of approximately equal length, both becoming progressively longer distally. Mandibles with light pigment on outer face. Maxillae with pigment on outer face of stipes, basal article of maxillary palp fairly dark; second, third and penultimate articles with dark patches at each end but little in their midsections; ultimate article with very light pigmentation. Labium with well pigmented glossae; ultimate article of labial palp pigmented along outer margin as well as on the most mediad margin. Legs with very strong pigmentation in some areas, notably along the outer margin of the coxae diminishing in intensity across the ventral face to about the middle, on the outer margin of the trochanter especially basally, on the femur along the posterior margin and adjacent to the tibia, on both ends of the tibia, apically on the basal article of the tarsus and somewhat lighter on the last tarsal article. Coxite VIII lightly pigmented around the stylet insertion, coxite IX also pigmented around the insertion but also over the face of the inner process. Stylets with strong pigmentation at each end but very little in the middle. Ovipositor showing slight pigmentation at the distal end of each division making it comparatively easy to discern the pseudosegmentation. Terminal filaments strongly banded, basally the dark and light bands are short and similar in length but both become progressively longer, however by the distal end the dark sections are much longer than the light sections.

Macrochaetae: Very light brown to hyaline and of variable form (Figures 2-7).
Scales: With sub-parallel ribs not very close together (Figures 8,9); darker dorsal scales with brown ribs that do not surpass the edge of the scales, ventral scales similar but hyaline, shape of scales generally round. Scales found on top of head, on scape, all nota, all thoracic sterna, legs except for tarsi, all urotergites and urosternites and stylets IX; absent from stylet VIII (?) and from the terminal filaments.

Head: Wider than long (Figure 10). Anterior margin of frons projected forward into distinct ridges over clypeus and bases of antennae. Margins of head laterally and anteriorly with stout setae not forming dense bushes, setae behind antennae accompanied by a long thin submarginal seta (Figure 2), a few stout setae before and one or two at the back of the eye. Clypeus with $1+1$ combs of long, pectinate macrochaetae as well as $3+3$ stout macrochaetae proximal and medial to these, as well as $2+2$ stout macrochaetae on the margins lateral and distal to the combs. Labrum with $1+1$ elongate groups of widely spaced, longer, pectinate macrochaetae as well as some simple setulae and cilia. Eyes dark brown of 12 ommatidia. Antennae incomplete in all specimens but fairly long, reaching about three quarters $\mathrm{H}+\mathrm{B}$. Scape (Figure 11) with scales over surface and short robust simple setae apically, pedicel with scales, some small setulae basally and a subapical rosette of simple setae, first interval or annulus of the flagellum with a few setulae and a tiny apical trichobothrium, second interval with two rosettes of setae and trichobothria and the first indication of subdivision, subsequent intervals subdivided into two annuli or chains with a hint of further subdivision, each annulus with one or two rosettes of setae and trichobothria in the T-annulus, tiny circular sensillae visible from the eighth interval. Most apical surviving intervals (Figure 12) without obvious trichobothria, forming intervals of five annuli, with pigment in the distal four annuli of every alternate interval. Basal and second annuli of each interval with a rosette of setae and sometimes a cilium, third annulus with basal rosette of setae and a more distal rosette with setae, cilia and some circular sensillae, fourth annulus with rosette of setae, fifth and ultimate annulus with two rosettes, the more basal of setae only, the more distal with at least two circular sensillae, at least one rod-like basiconic sensillae and several cilia. This patterns need to be confirmed with more specimens and preferably using SEM Mandibles (Figures 13, 14) with molar and large incisor areas; a group of about eight apically bifurcated but simple setae distally adjacent to the molar area, the most distal being very short and stout, and a bush of about 30 macrochaetae externally. Maxilla (Figures 1517) with one stout pectinate macrochaeta, one smooth macrochaeta and a small seta externally proximal to the palp, the lacinia with two teeth, followed by about four lamellate processes and a row of four, apically bifurcate setae, galea surpassing the apex of the lacinia; palp without strong setae although a rosette of slightly 


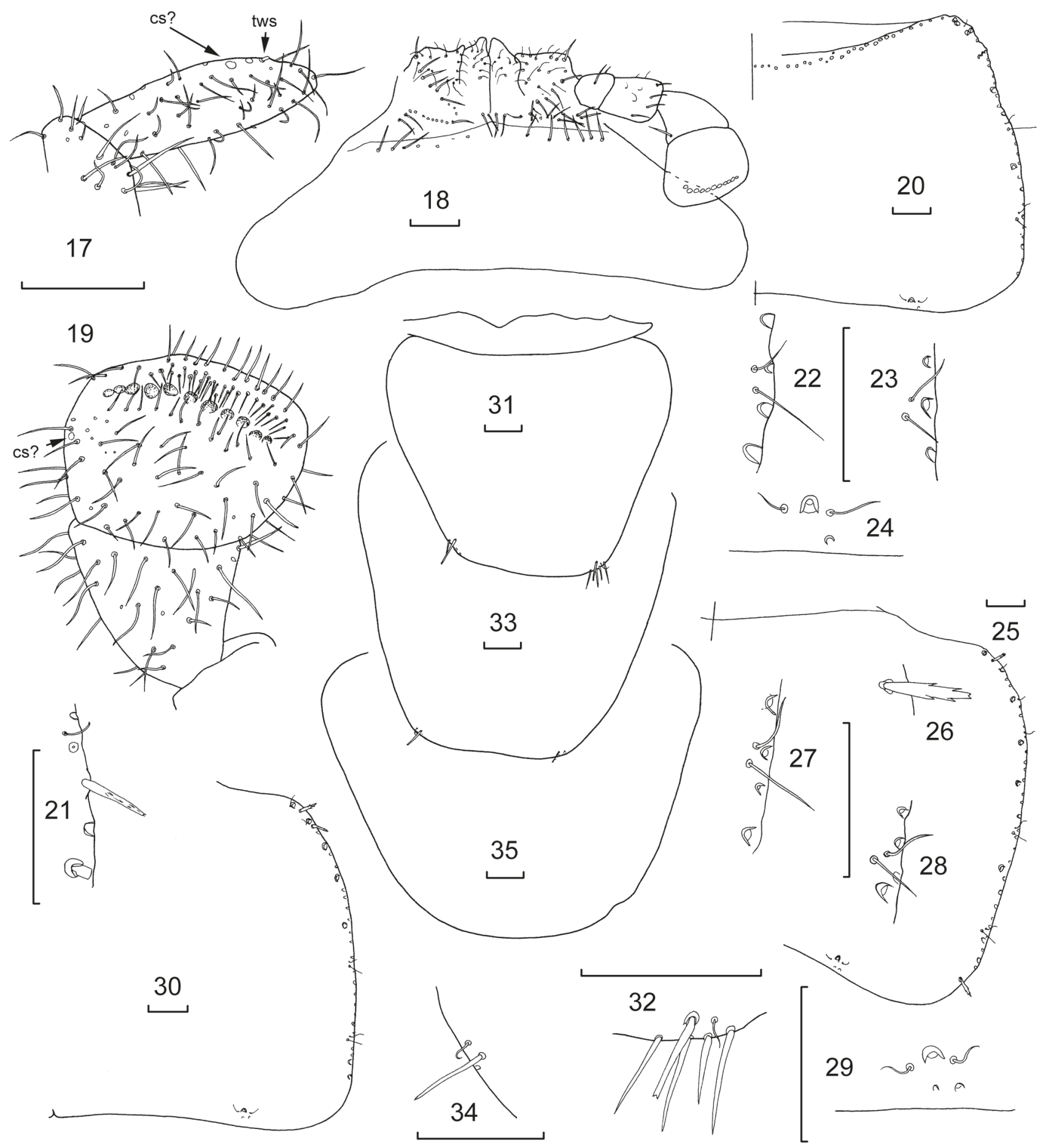

FIGURES 17-35 Qantelsella maculosa sp. nov., holotype female (WAM E88546) unless otherwise noted by specimen number: 17, maxilla, ultimate article of palp showing possible circular sensilla (cs?) and thin-walled basiconic sensilla (tws); 18, labium, one palp missing; 19, idem, ultimate article of palp, showing possible circular sensilla (cs?); 20, pronotum, right half; 21, idem, macrochaeta on lateral margin (K261101); 22, idem, anterior trichobothrial area; 23, idem, posterior trichobothrial area; 24, idem, posterior comb; 25, mesonotum, right side; 26, idem, macrochaeta from posterolateral corner; 27 , idem, anterior trichobothrial area; 28, idem, posterior trichobothrial area; 29, idem, right posterior comb, 30, metanotum; 31, prosternum; 32, idem, posterolateral chaetotaxy, 33, mesosternum; 34, idem, posterolateral chaetotaxy; 35, metasternum. All scale bars $=0.1 \mathrm{~mm}$. 


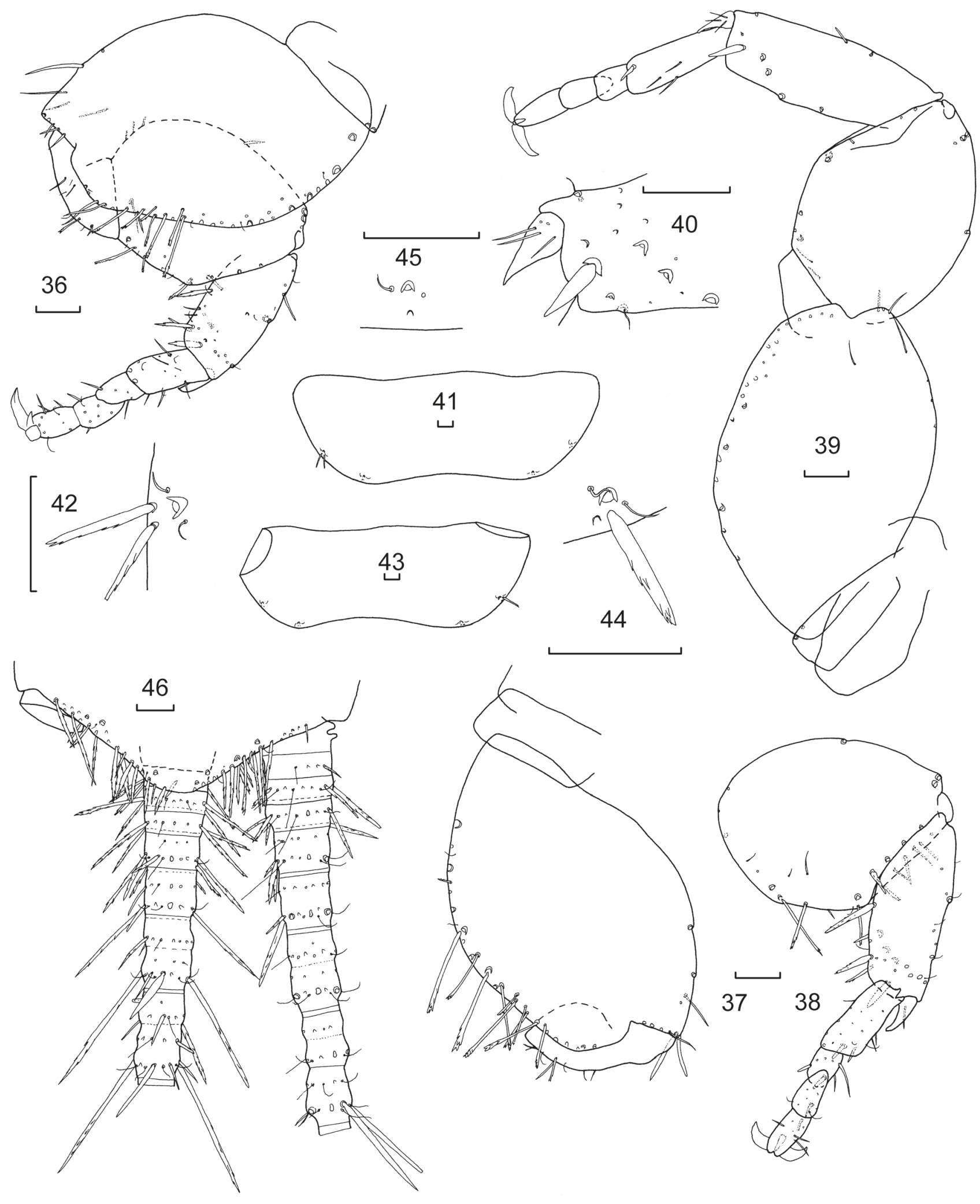

FIGURES 36-46 Qantelsella maculosa sp. nov., holotype female (WAM E88546) unless otherwise noted by specimen number: 36, PI; 37, PII, coxa and trochanter; 38, PII, femur, tibia and tarsi; 39, PIII (WAM E88549); 40, idem, end of tibia; 41, urotergite $V ; 42$, idem, marginal setae of left lateral comb; 43, urotergite $V I ; 44$, idem, macrochaeta of right lateral comb; 45, submedial comb of urotergite $\mathrm{IV} ; 46$, urotergite $\mathrm{X}$ and base of terminal filaments. All scale bars $=0.1 \mathrm{~mm}$. 
stronger setae near the apex of the second article, apical article of maxillary palp (Figure 17) 2.2 times longer than wide (range 1.6-3.0) and 1.3 times longer than penultimate article (range 1.2-1.4), the sensillae of the ultimate article ambiguous, possibly one thin-walled basiconic sensilla (type C of Adel, 1984) subapically and some small rod-like basiconic sensillae (type B of Adel, 1984) near it and possibly a small circular sensilla. Labium (Figure 18) short and broad with rows of short strong setae on the prementum, glossae and paraglossae broad with transverse and oblique rows of setae, apically with short curved setulae; labial palp short, apical article expanded medially (Figure 19), 0.85 times longer than wide (range $0.77-0.96$ ) with row of 11 or 12 papillae of compact type arranged in a single row, possibly with small circular sensilla on the outer margin, covered with numerous fine short setae as well as longer fine setae on along the distal end.

Thorax: Pronotum (Figure 20) with single row of macrochaetae forming notal collar (all macrochaetae lost except for the most lateral on both the dissected holotype and paratype, where it is short and pectinate (Figure 6); lateral margins with a few small stout pectinate setae, three combs of two (sometimes only one) macrochaetae (most lost except most anterior one on paratype which is long and quite pectinate similar to that illustrated in figure 3 from anterior margin of frons) and one macrochaeta on margin of paratype in the anterior quarter with another two single submarginal macrochaetae in the next half of the margin but otherwise only marginal setae (Figure 21). Two very small open trichobothrial areas; the anterior area (Figure 22) is about almost half the way along the margin with the trichobothrium almost on the margin and only associated with a cilium (no macrochaeta). Posterior trichobothrial area (Figure 23) located about three quarters the distance along the margin and similarly inconspicuous, almost on the margin and not associated with a macrochaeta; the hairs of both trichobothria are very short (not more than twice the length of the adjacent cilia). Posterior margin with $1+1$ single macrochaetae each associated with one or two submarginal setulae and a cilium on each side (Figure 24). Mesonotum (Figure 25) with lateral and posterior chaetotaxy similar to pronotum with five or six single submarginal macrochaetae (but not forming combs of two) along the anterior two thirds of the margins; marginal setae mostly lost except most posterior (Figure 26). Both trichobothrial areas similar to those on the pronotum i.e. very tiny trichobothria, close to the margin and associated with a similar sized cilium; the anterior trichobothrial area (Figure 27) located about halfway along the lateral margin and the posterior trichobothrial area (Figure 28) about three quarters the distance along the margin. Posterior margin with $1+1$ combs (Figure 29) each consisting of a single macrochaeta with a cilium on each side and one to three setulae between the macrochaeta and the margin. Metanotum (Figs 30) similar to mesonotum.

Presternum narrow and glabrous (Figure 31). All thoracic sterna with hyaline scales. Prosternum (Figure 31) large rounded trapezoidal, almost as long as the corresponding coxa, slightly wider at its base than long, anterolateral corners glabrous, posterior-lateral corners with $1+1$ single submarginal pectinate macrochaetae, three or four fine simple marginal setae and a cilium (Figure 32). Mesosternum (Figure 33) also rounded trapezoidal, as long as the corresponding coxa, as long as wide at its base, each posterior corner with a small submarginal pectinate seta and perhaps a cilium and a couple of marginal setulae (Figure 34). Metasternum (Figure 35) with round posterior margin, not strongly trapezoidal, about 1.2 times wider than long, glabrous.

Legs quite widely spaced and quite stout, tibia L/W ratio of legs PI 2.0 (range 1.91-2.08), PII 2.2 (2.0-2.33), PIII 2.7 (2.25-3.17); tarsi L/W ratio PI 4.3 (range 3.69-5.43), PII 4.4 (3.29-5.56), PIII 5.2 (4.0-6.0). PI (Figure 36) with lateral comb of two macrochaetae on precoxa. Coxa with scales, external margin with longer and shorter pectinate macrochaetae and some cilia, some simple stout setae in the more distal part, internal margin with some simple setae distally and over the articulation with the trochanter, a few fine setae on ventral face. Trochanter with one short thin pectinate macrochaeta and some fine setulae. Femur with scales both ventrally and dorsally, posterior margin with several pectinate macrochaetae, anterior margin with one seta medially and two stronger macrochaetae distally (only insertion sockets remaining). Tibia of PI with some stout pectinate macrochaetae on the ventral margin, especially distally and also midway along the dorsal margin as illustrated; apex of tibia with a stout pectinate macrochaeta which is shorter than the glabrous apical spur. Tarsi with four articles, the basal article of PI about $40 \%$ of the total length of the tarsus, its joint with the next article not as oblique as that between the second and third articles, all tarsal articles with some short setae, of which some ventrally are more robust with slightly rounded tips, as well as some cilia. Pretarsus with two long curved lateral claws and a much shorter curved medial claw. PII (Figures 37, 38) and PIII (Figures 39) similar to PI; with PII only slightly longer than PI, but PIII noticeably longer. Apical spur of tibia with one or two setae on PII and about four or five on PIII (Figure 40).

Abdomen: Urotergite I with 1+1 lateral combs of a single macrochaeta with a cilium on each side and two setulae on or near the margin. The macrochaetae have been lost from all segments, however one short, fairly robust pectinate macrochaeta from the right lateral comb on urotergite VI of the holotype is aligned in a way that suggests it came from the macrochaeta socket. Urotergites II-VIII (Figures 41-45) with 2+2 combs each of a single macrochaeta (mostly lost but those on $\mathrm{V}$ are fairly robust and pectinate); all combs also 


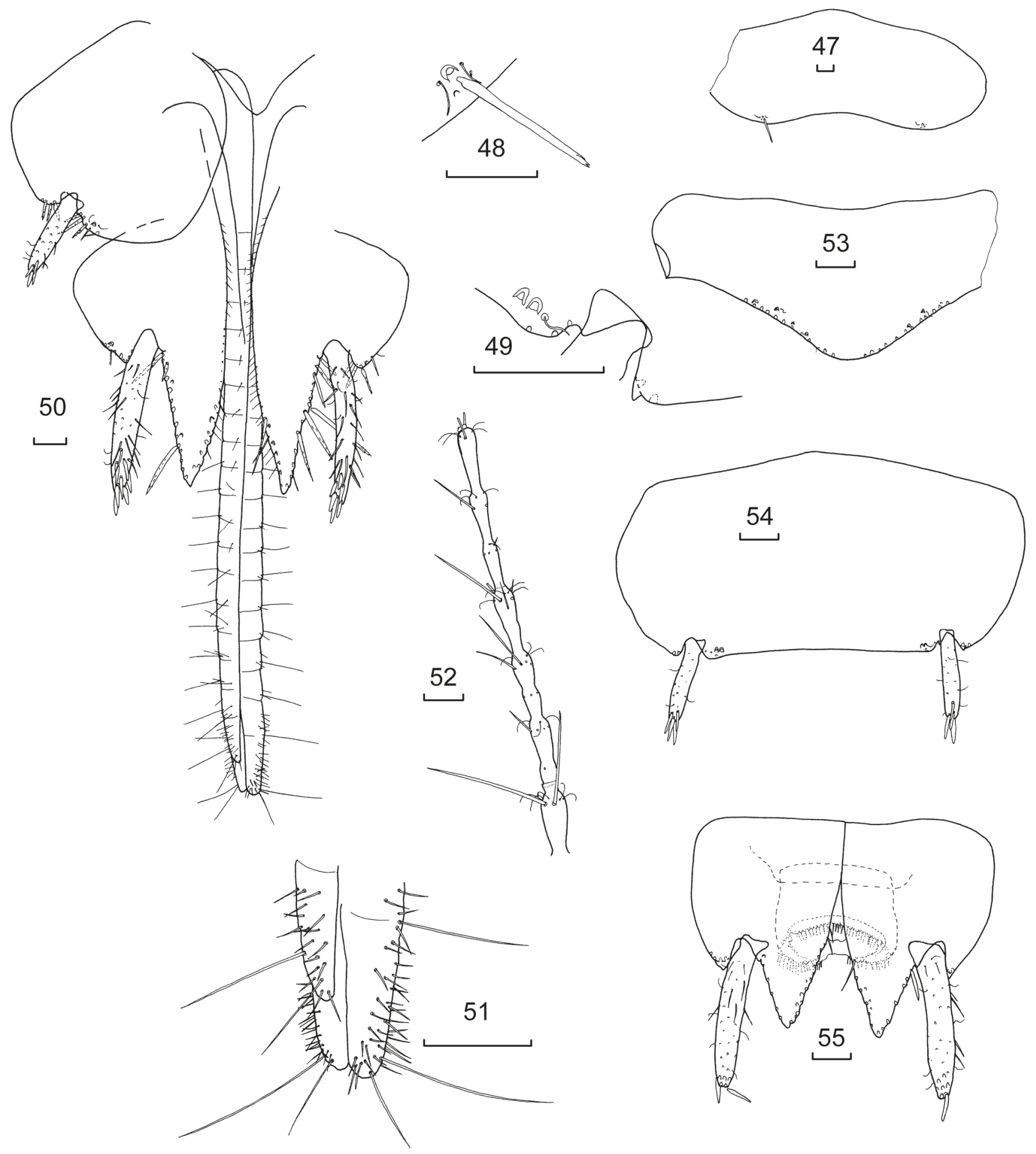

FIGURES 47-48, 51-52 Qantelsella maculosa sp. nov., holotype female (WAM E88546).

FIGURES 49-50,53-55 Qantelsella maculosa sp. nov., paratype male (WAM E88549): 47, urosternite V(?); 48, idem, right comb; 49, urosternite VIII, left stylet insertion; 50, urosternites VIII, IX, stylets and ovipositor; 51, ovipositor, detail of apical divisions; 52, cerci, most distal surviving divisions; 53, urotergite $X$ of male; 54, urosternite VIII of male and stylets; 55, coxites IX of male, penis and stylets. All scale bars $=0.1 \mathrm{~mm}$. 
TABLE 1 Number of macrochaetae per bristlecomb Qantelsella maculosa sp. nov.

\begin{tabular}{l|lll|} 
& \multicolumn{2}{|c|}{ Urotergite } & \\
Segment & Lateral & Submedial & Urosternite \\
\hline I & 1 & 0 & 0 \\
II & 1 & 1 & 0 \\
III & $0-1$ & 1 & 1 \\
IV & 1 & 1 & 1 \\
V & 1 & 1 & 1 \\
VI & 1 & 1 & 1 \\
VII & 1 & 1 & $1-2$ \\
VIII & 1 & 1 & 2 \\
IX & 0 & 0 & 0 \\
\hline
\end{tabular}

associated with 0-3 marginal setae and a cilium on one or either side of the macrochaeta (Figures 42, 44, 45). The macrochaeta insertion is missing from the lateral comb of urotergite III of the holotype but the cilia and setae insertions are present. Urotergite IX glabrous. Urotergite X (Figure 46) short rounded subtriangular, much wider than long (L/W at base about 0.30 ) with many strongly pectinate setae along entire margin, both above and below, with $3+3$ submarginal macrochaetae (all lost and only visible from insertion sockets).

Urosternites I and II glabrous, urosternites III-VIII with 1+1 lateral combs each of just a single macrochaeta with a cilium on each side and one or two submarginal setae (all lost), most macrochaetae lost except one on urosternite V(?) and one on VII(?) both of which are apically pectinate and about one quarter as long as the respective urosternites (Figures 47, 48). On the male paratype, one of the combs on urosternite VII(?) and both combs on urosternite VIII are composed of two macrochaetae, two cilia and one or two submarginal setae. The combs on urosternite VIII are mediad to the stylet insertion (Figure 49); urosternite VIII with four or five pectinate setae on the margins on both sides adjacent to the stylets.

Two pair of stylets present in both sexes (Figures $50,54,55)$; those on VIII about half as long as those on IX, with four (?) stout, darker, rounded macrochaetae apically. Stylets IX with six or seven, similar macrochaetae; these stylets are only slightly longer than the internal processes.

Genital region of $q$ as in figure 50, the internal process of coxite IX fairly long, twice as long as wide at its base and about four times longer than the short external process. Apex of internal process acute with slightly pectinate macrochaetae along much of the margins. Ovipositor of medium length (up to 2.0 times $\mathrm{HW}$ ), in holotype surpassing the apex of the inner processes by about twice the length of these processes, consisting of about 20 divisions; of primary type with numerous short and two very long, thin setae on the last division of the gonapophyses (Figure 51).

Cerci (Figs 46, 52) with four basal divisions shorter than wide then progressively longer with setae, pectinate macrochaetae and trichobothria becoming increasingly stronger and longer distally, fifth division showing first signs of subdivision with two rosettes, distinctly subdivided by seventh division which also shows signs of further subdivision with a nascent second rosette present in each annulus; macrochaetae progressively becoming less pectinate distally; most distal surviving division $\left(14^{\text {th }}\right)$ divided into eight annuli (Figure 52). Median dorsal appendage (Figure 46), first division glabrous, next division with pectinate setae, following divisions also short with pectinate setae and trichobothria in increasing numbers as well as long pectinate macrochaetae laterally and below, fifth division longer with second rosette of very small setae and trichobothria, sixth division as long as wide, seventh division indistinctly divided into two annuli, the distal dorsal macrochaeta being noticeably darker, broader and smoother than the others, further divisions becoming increasingly longer and the macrochaetae becoming much less pectinate. Divisions beyond the tenth lost in holotype.

Male: Similar to female except urotergite $\mathrm{X}$ (Figure 53) slightly shorter (L/W 0.25 ) and only $1+1$ macrochaetae obvious (possibly due to smaller size of specimen), coxites VIII not divided (Figure 54), internal process of coxites IX not as elongated, about 2.6 times longer than the external process but slightly longer than broad at its base, only a little longer than half the length of the stylets; external and internal margins of internal process with macrochaetae (presumably all stout and not pectinate based on the small number of surviving setae). Outer process small, triangular with a few setae on the hidden upper side of its apex. Penis typical with numerous glandular setae apically (Figure 55). Parameres absent.

\section{ETYMOLOGY}

The species is named from the Latin word maculosus meaning mottled or stained, referring to the appearance of the scales in alcohol as well as the very dark pigment patches on the legs.

\section{HABITAT}

Only nine specimens of this species from six different sites were found among the extensive Barrow Island material. These were collected in both natural and disturbed habitats, including limestone flats and low ridges and coastal dunes. They were taken in pitfall traps, in Winkler sack litter samples and one by suction sampling of vegetation, giving little indication of the preferred habitat of the species. The curved tarsi may suggest climbing on thin objects but this is purely conjecture. 
Qantelsella aurantia sp. nov.

http://zoobank.org/NomenclaturalActs/F9E9E067C24B-4179-89D9-B45CBB7206B2

Figures 56-106

\section{MATERIAL EXAMINED}

\section{Holotype}

Australia: Western Australia: $\hat{\text { ô }}$ (HW 0.71), Barrow Island, site GP7 (337722, 7699467), 15 March 2006, S. Callan, R. Graham, PIT (WAM E89198) on two slides.

\section{Paratypes}

Australia: Western Australia: $q$ (HW 0.75), same data as holotype (WAM E89199) on two slides; + (HW0.70), same data as holotype (WAM E89200) in alcohol; ㅇ (HW 0.70), Barrow Island, site CC1 (337391, 7697313), 25 September 2006, S. Callan, R. Graham, PIT (WAM E89201) on two slides; $\widehat{o}$ (HW 0.70), same data as previous (WAM E89202) in alcohol; $\widehat{O}$ (HW 0.68), same data as previous, 25 September 2006 (WAM E89203) in alcohol; $\widehat{\partial}$ (HW 0.73), same data as previous (WAM E89204) in alcohol; + (HW 0.68), same data as previous (WAM E89205) in alcohol; + (HW 0.70), same data as previous (WAM E89206) in alcohol; $\hat{\sigma}$ (HW 0.70), Barrow Island, site GP5 (338740, 7701088), 15 March 2006, S. Callan, R. Graham, PIT (WAM E89207) in ethanol; क (HW 0.75), Barrow Island, site GP8 (337670, 7699230), 15 March 2006, S. Callan, R. Graham, PIT (WAM E89208) in alcohol; + (HW 0.78), same data as previous (WAM E89209) in alcohol; juvenile $\delta$ (HW 0.58), same data as previous (WAM E89210) in alcohol.

\section{Other material examined in detail but not included in types series:}

Australia: Western Australia: juvenile $\hat{\delta}$ (HW 0.58), Barrow Island, site N13 (332808, 7694467), 6 May 2006, S. Callan, R. Graham, PIT D (AMS K261096, K261097) on two slides; juvenile $\widehat{\delta}$ (HW 0.63), same data as previous (AMS K377615) in alcohol; subadult $q$ (HW 0.63), Barrow Island, site N15 (336732, 7698579), 1 May 2007, S. Callan, K. Edwards, PIT (AMS K377616) in alcohol; $\delta$ (HW 0.65), Barrow Island, site CC1 (337391, 7697313), 25 September 2006, S. Callan, R. Graham, PIT (AMS K377617) in alcohol; ㅇ (HW 0.68), Barrow Island, site GTPZ1SUC5 (338419, 7699767), 19-30 March 2012, N. Gunawardene, C. Taylor (AMS K377618) in alcohol; ô (HW 0.60), Barrow Island, site N05b (334218, 7692088), 1 May 2007, S. Callan, K. Edwards, PIT (AMS) used for scanning electron microscopy.

\section{DIAGNOSIS}

This species can easily be distinguished from other species of Qantelsella by the presence of combs rather than groups of macrochaetae on the labrum, by its reddish eyes (in alcohol), by the distinct tawny orange colouring of the macrochaetae and the more posterior abdominal segments, by the cordiform and rounded thoracic sterna and by the presence of only a single pair of stylets (see discussion on generic placement).

\section{DESCRIPTION}

Appearance: Body not elongate with thorax only slightly wider than abdominal segment $\mathrm{I}$, the following abdominal segments about the same width until the sixth and only narrowing slightly towards the posterior end (Figure 56). Appearance when live unknown; in alcohol mottled brown or somewhat orange without distinct pigment markings; eyes reddish. Dorsally covered with brown scales.

Body size: $\mathrm{H}+\mathrm{B}$ length up to about $5.4 \mathrm{~mm}$ (?), $4.0 \mathrm{~mm}$ (ठ)); maximum head width $0.78 \mathrm{~mm}$; thorax: length up to $1.5 \mathrm{~mm}$ or 0.29 times $\mathrm{H}+\mathrm{B}$ (range $0.24-0.33$ ); width up to $1.05 \mathrm{~mm}$ with no great difference in the relative width of the nota, meso and metanota only slightly shorter than the pronotum; antennae probably incomplete in all specimens, maximum surviving length of antenna 3.5 $\mathrm{mm}$ or 0.65 times estimated $\mathrm{H}+\mathrm{B}$; terminal filaments quite long, maximum surviving length of cercus 2.25 $\mathrm{mm}$ or $0.70 \mathrm{H}+\mathrm{B}$; maximum length of intact median appendage $2.30 \mathrm{~mm}$ (up to $0.72 \mathrm{H}+\mathrm{B}$ ).

Pigmentation: Orange-brown. Head without distinct pigmentation. Pedicel and scape with pigment; flagellum evenly brown. Mandibles with light pigment on outer face. Maxillary palp overall, slightly orange, with more pigment in the penultimate and ultimate articles. Labium with weak bands of pigment at sides of prementum; ultimate article of labial palp slightly pigmented. Legs with pigmentation, notably distally on the outer margin of the femur and most strongly on the tibia and on the basal article of the tarsus. Coxite IX pigmented or sclerotised, somewhat orange in colour, with its stylet distinctly lighter in colour. Ovipositor slightly orange overall. Terminal filaments evenly brown.

Macrochaetae: Very orange-brown to hyaline, of variable form (Figures 57, 58).

Scales: (Figures 59, 60) of variable shape with subparallel brown ribs that do not surpass the edge of the scales, ventral scales similar. Scales found on top of head, on scape, mandibles, all nota, all thoracic sterna, legs except for tarsi, all urotergites and urosternites and stylets IX and a few appear to be present basally on the terminal filaments (?).

Head: Wider than long (Figure 61). Anterior margin of frons not projected forward into distinct ridge over clypeus and bases of antennae. Lateral margins of head behind antennae with rows of stout pectinate macrochaetae and a long thin seta (trichobothria?) a little remote from the margin; two macrochaetae posterior to the eyes, anterior margin of head with $1+1$ weak bushes with some setae aligned in rows two to 


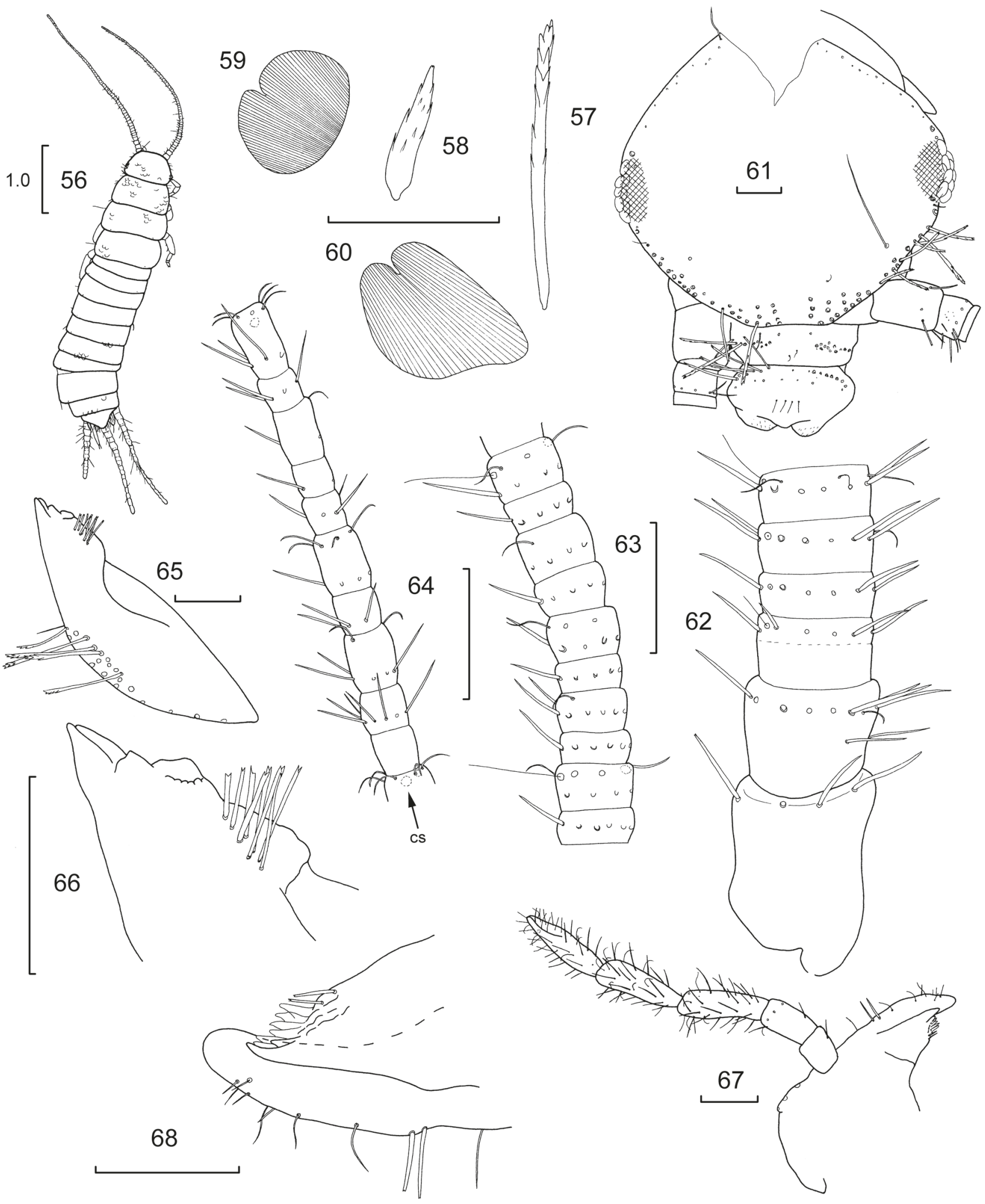

FIGURES 56-68 Qantelsella aurantia sp. nov., holotype male (WAM E89198) unless otherwise noted by specimen number: 56, habitus composite drawing, head and body of WAM E89206, antennae of WAM E89201; 57, macrochaeta from clypeus; 58, macrocheta from tibia of PI; 59; scale from middle of pronotum; 60, scale from posterior margin of urosternite VIII; 61, head (cross-hatched areas obscured by eye pigment); 62, antenna, scape, pedicel and basal intervals of flagellum (WAM E89201); 63, idem, section of antenna at about one third the length of the antenna (WAM E89201); 64, idem, most distal surviving interval showing possible circular sensilla (cs) on opposite side of antenna (WAM E89201); 65, mandible; 66, idem, distal end; 67, maxilla; 68, idem, distal end of lacinia and galea. Scale bars = $0.1 \mathrm{~mm}$ unless otherwise indicated. 
four macrochaetae long. Clypeus with $1+1$ irregular bushes of long pectinate macrochaetae. Labrum with $1+1$ combs of long pectinate macrochaetae as well as some simple setulae anteriorly. Eyes reddish in alcohol, of about 12 ommatidia. Antennae incomplete in all specimens but fairly long, reaching about two thirds $\mathrm{H}+\mathrm{B}$. Scape (Figure 62) with scales over surface and short robust simple setae apically, pedicel without scales, with a subapical rosette of simple setae and cilia as well as some thinner setae proximally, first interval of flagellum indistinctly subdivided with a rosette of setae and a trichobothrium subapically, following intervals similar but becoming gradually longer, and with more cilia; intervals divide into two annuli by presumed fifth interval and five annuli by the presumed seventh interval, then six and finally eight annuli (Figure 63). The trichobothria are no longer visible beyond the basal third of the flagellum. Specialised sensillae could not be observed under the light microscope but both circular (poculiform?) and rod-like basiconic sensillae were present (Figures. 64, 105 and 106); the specimen needs to be correctly aligned if they are to be seen. Mandibles (Figures 65, 66) with molar and large incisor areas; a group of four to eight apically bifurcated but smooth setae distally adjacent to the molar area and a bush of about 30 pectinate macrochaetae externally. Maxilla (Figures 67, 68) with three long pectinate macrochaetae on stipes posterior to the scape, the lacinia with two teeth, followed by about six lamellate processes and two simple or apically bifurcate setae, galea surpassing the apex of the lacinia; palp without strong setae, apical article of maxillary palp 3.6 times longer than wide (range 2.8-4.75) and 1.3 times longer than penultimate article (range 1.11-1.46), the sensillae of the ultimate article ambiguous, possibly one circular sensilla and one or more small rod-like basiconic sensillae near the apex (?). Labium (Figure 69) with row of short strong setae on the prementum largely interrupted in the medial region, glossae and paraglossae with transverse and oblique rows of setae, apically with short curved setulae; apical article of labial palp not expanded medially (Figure 70), about as long as wide (range 0.84-1.25) covered with fine short setae as well as longer fine setae on along the distal end and with row of six to ten papillae (not clearly seen in most specimens) of compact type arranged in a single row; other sensillae not identified.

Thorax: Pronotum (Figure 71) with single row of macrochaetae forming notal collar, the macrochaetae in the medial region much shorter than those laterally; lateral margins with a few small stout weakly pectinate setae in the anterior two thirds, becoming longer and stronger towards the posterior corner, each margin with two anterior combs each of two pectinate macrochaetae followed by two single submarginal macrochaetae, the first associated with the anterior trichobothrium. Two open trichobothrial areas; the anterior area (Figure 72) is about one quarter the way along the margin with the trichobothrium located between a macrochaeta and the margin. Posterior trichobothrial area (Figure 73) located about two thirds the distance along the margin with a macrochaeta located between the trichobothrium and the margin (absent on the right side in the holotype); the hairs of both trichobothria are not long, being much shorter than the longest marginal macrochaeta. Posterior margin with $1+1$ single macrochaetae each associated with a cilium and sometimes a marginal setula (Figure 74), the macrochaeta insertion is missing on the left side in the holotype. Mesonotum (Figure 75) slightly longer than pronotum with lateral and posterior chaetotaxy similar to pronotum, each side with two anterior combs each of two pectinate macrochaetae and three submarginal single macrochaetae; marginal setae mostly lost but those remaining are short tapering and with almost indistinct pectinations. Anterior trichobothrial areas (Figure 76) about one third the way along the margin, with a short trichobothrium almost on the margin, laterad to a single macrochaeta. The posterior trichobothrial area located about three quarters the distance along the margin (Figure 76) with a macrochaeta and a cilium between the trichobothrium and the margin. Posterior margin with $1+1$ combs similar to pronotum. Metanotum (Figure 77) slightly longer than mesonotum, with two combs each of two macrochaetae in the anterior half and only one submarginal macrochaeta in the posterior half, which is associated with the anterior trichobothrium (Figure 78). The posterior trichobothrial areas without a submarginal macrochaeta in holotype but one is present in paratype (WAM E89199) (compare Figures 78 and 79). Posterior margin as for pro- and mesonota.

Presternum narrow and with a few small setae (Figure 80). All thoracic sterna with hyaline scales. Prosternum (Figure 80) not large, parabolic, only a little more than half the length of the corresponding coxa, slightly wider at its base than long, anterolateral corners glabrous, posterior third with long thin marginal setae, $1+1$ stronger setae near the apex and one to three short combs of one to three pectinate macrochaetae on each side (compare figures 81 and 82 of holotype and paratype). Mesosternum (Figure 83) slightly larger than prosternum but also parabolic and about as long as wide at its base, a little more than three quarters as long as the corresponding coxae, posterior apex with $1+1$ subapical combs each of two or three pectinate macrochaetae and sometimes a longer smooth seta further apically (only present on right side in holotype and paratype WAM E89199) and one or two fine setae on the margin of each side (Figure 84). Metasternum (Figure 85) also wider than long and parabolic with $1+1$ subapical combs each of two or three pectinate macrochaetae and two marginal setae near each comb (Figure 86).

Legs (Figures 80, 87, 88) quite stout, tibia L/W ratio of legs PI 2.4 (range 1.55-2.94), PII 2.6 (2.22-3.50), 

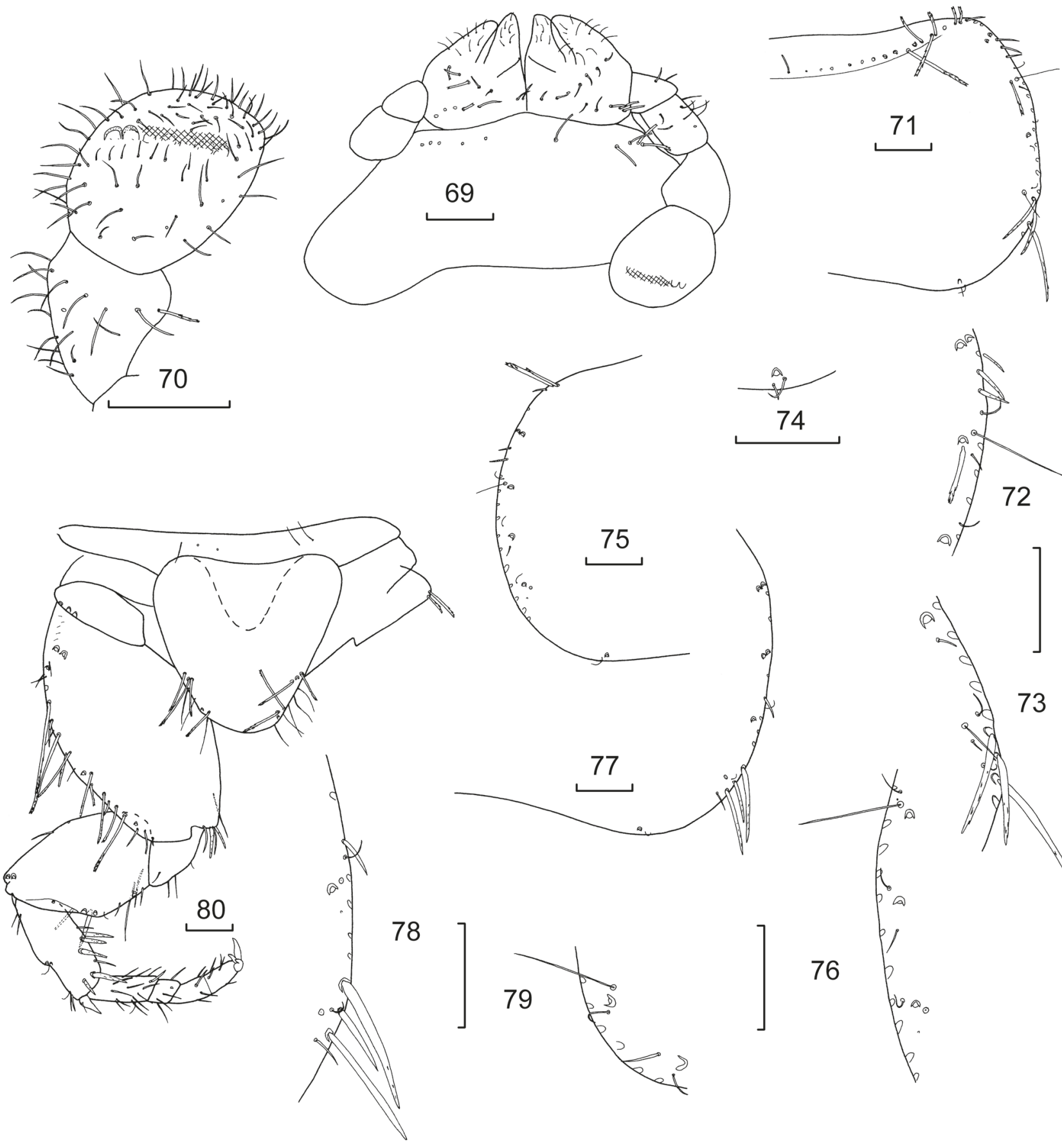

79
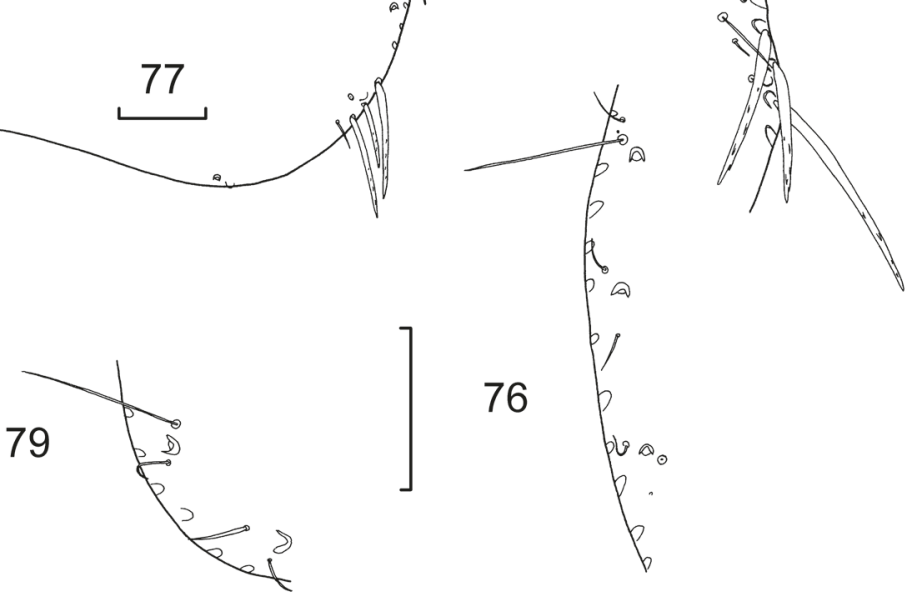

FIGURES 69-80 Qantelsella aurantia sp. nov., holotype male (WAM E89198) unless otherwise noted by specimen number: 69, labium; 70, idem, ultimate article of palp; 71, pronotum, right half; 72, idem, anterior trichobothrial area; 73, idem, posterior trichobothrial area; 74, idem, posterior comb; 75, mesonotum, left half; 76, idem, part of left margin with both anterior and posterior trichobothrial areas; 77, metanotum, right half; 78, idem, posterior part of right margin with both anterior and posterior trichobothrial areas; 79, left posterior trichobothrial area of metanotum (WAM E89199); 80, presternum, prosternum and $\mathrm{PI}$. All scale bars $=0.1 \mathrm{~mm}$. 
PIII 2.9 (2.15-3.33); tarsi $\mathrm{L} / \mathrm{W}$ ratio PI 4.6 (range 3.17-5.33), PII 5.0 (4.50-5.38), PIII 6.6 (5.14-8.0). PI (Figure 80) with lateral comb of two to three short macrochaetae on precoxa. Coxa with anterolateral comb of two macrochaetae and a row of long pectinate macrochaetae and some small setae along the outer margin, internal margin with some short stout pectinate macrochaetae distally over the articulation with the trochanter. Trochanter with a few simple setae. Femur with about six stout pectinate macrochaetae on posterior margin, anterior margin with one seta medially and two stronger macrochaetae distally (only insertion sockets remaining). Tibia of PI with some stout pectinate macrochaetae on the ventral margin and also midway along the dorsal margin as illustrated; apex of tibia with a stout pectinate macrochaeta which is longer than the apical spur. Tarsi with four articles, the basal article of PI about $40 \%$ of the total length of the tarsus, its joint with the next article about as oblique as that between the second and third articles, all tarsal articles with some short setae, some of which ventrally are more robust, as well as some cilia. Pretarsus (Figure 89) with two long curved lateral claws and a much shorter curved medial claw. PIII noticeably longer with stout pectinate macrochaeta at the end of the tibia about twice the length of the apical spur, first article of tarsus equal in length to the remaining three articles together. Apical spurs of tibiae of all legs usually with one seta (Figure 90).

Abdomen: Urotergite I with 1+1 lateral combs each of a single pectinate macrochaeta with one or two marginal setulae. The macrochaetae have been lost from all segments of the holotype except for one submedial on urotergite IV and a lateral on urotergite VI. Urotergites II-VIII (Figure 91) with $2+2$ combs, the lateral combs consisting of only one macrochaeta in the anterior segments and two in the posterior segments (Figure 92), each lateral comb associated with one or two cilia and one or two marginal setulae; the submedial combs (Figure 93) with just a single macrochaeta associated with a laterad cilium and in one case a marginal setula. Urotergite IX glabrous. Urotergite X (Figure 94) short rounded subtriangular, about three times wider than long at base with many strongly pectinate setae along entire margin, both above and below, except for the apex, with $3+3$ submarginal pectinate macrochaetae. In some specimens, especially smaller ones, urotergite $\mathrm{X}$ can be quite round, rather than rounded subtriangular, and sometimes even slightly truncated.

Urosternite I and II glabrous, urosternites III-VIII (Figure 95) each with 1+1 lateral combs of one to four macrochaetae with a cilium on the laterad end of each comb and one marginal seta. Most macrochaetae lost in holotype except for one macrochaeta of each comb of urosternite VII(?), where one is quite long (about one third the length of the respective urosternite) and distinctly pectinate and the other appears short and constricted apically (Figures 96, 97).
TABLE 2 Number of macrochaetae per bristlecomb Qantelsella aurantia sp. nov.

\begin{tabular}{|c|c|c|c|}
\hline \multirow[b]{2}{*}{ Segment } & \multicolumn{2}{|c|}{ Urotergite } & \multirow[b]{2}{*}{ Urosternite } \\
\hline & Lateral & Submedial & \\
\hline I & 1 & 0 & 0 \\
\hline II & 1 & 1 & 0 \\
\hline III & $1-2$ & 1 & 3 \\
\hline IV & 1 & 1 & $3-4$ \\
\hline V & 2 & 1 & $3-4$ \\
\hline VI & 2 & 1 & $1-4$ \\
\hline VII & 2 & 1 & $3-4$ \\
\hline VIII & 2 & 1 & $3-4$ \\
\hline IX & 0 & 0 & 0 \\
\hline
\end{tabular}

Only one pair of stylets present in both sexes (Figure 98), being about twice the length of the inner process of coxite IX in the male. Stylets with about four smooth macrochaetae apically and more in along the ventral face.

Male genital region (Figure 98), coxites VIII not divided, internal process of coxites IX about three times longer than the small external process but slightly shorter than broad at its base, about half the length of the stylets; external and internal margins of internal process with numerous macrochaetae with a submarginal row extending to the base of the stylet, the macrochaetae inserted on the dorsal side of the margin more pectinate than those inserted on the ventral face. Outer process small, triangular with a few short, stout pectinate macrochaetae above and below the outer margin. Penis typical for family with numerous glandular setae apically (Figure 98). Parameres absent.

Cerci (Figures 99, 100) with three basal divisions shorter than wide, basal division glabrous, second and third with single rosette of setae, pectinate macrochaetae, cilia and trichobothria, divisions then progressively longer. Division four with two rosettes, the proximal rosette with setae and trichobothria, the distal with setae, pectinate macrochaetae, cilia and trichobothria, fifth division similar but longer and lacking trichobothria in distal rosette, sixth division with two annuli and three rosettes, the proximal two with setae and trichobothria, the distal with macrochaetae cilia and setae. Division seven with four annuli. A few scales visible on basal four or five divisions. The macrochaetae become less pectinate distally. Most distal surviving division (ninth) (Figure 100) divided into five annuli without clear divisions between them. Median filament (Figures 99, 101) with first division short, glabrous, next three divisions also short but with single rosette of pectinate setae, fifth division longer than wide with two rosettes of pectinate macrochaetae, those distally much longer and also stronger with some 


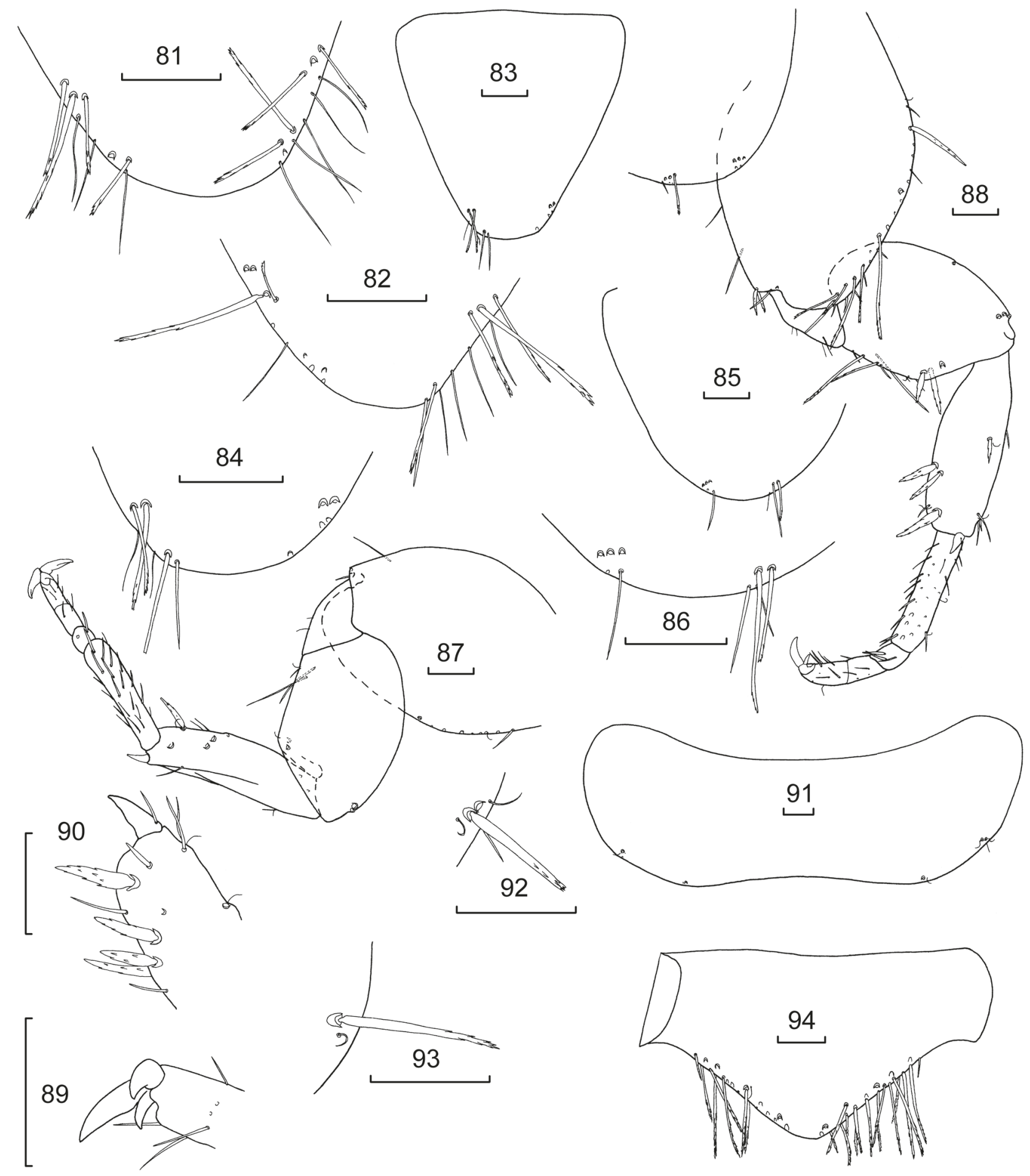

FIGURES 81-94 Qantelsella aurantia sp. nov., holotype male (WAM E89198) unless otherwise noted by specimen number: 81, prosternum, detail of chaetotaxy; 82, idem (WAM E89199); 83, mesosternum; 84, idem, detail of chaetotaxy; 85, metasternum; 86, idem, detail of chaetotaxy; 87, PII (WAM E89199); 88, PIII (WAM E89201); 89, pretarsus of PI; 90, apex of tibia of PI; 91, urotergite III; 92, lateral comb of urotergite VI; 93, submedial comb of urotergite IV; 94 , urotergite X. All scale bars $=0.1 \mathrm{~mm}$. 


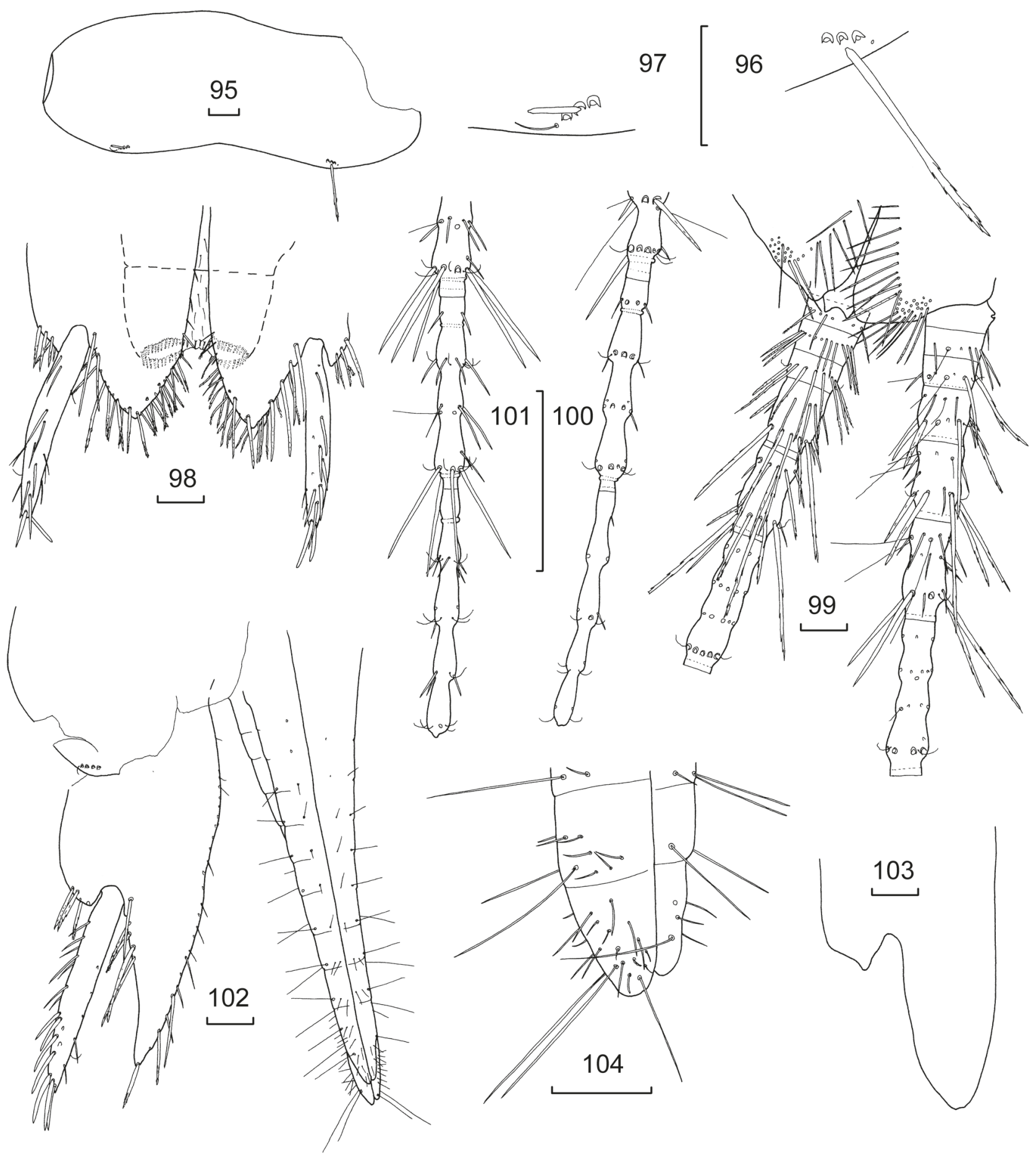

FIGURES 95-104 Qantelsella aurantia sp. nov., holotype male (WAM E89198) unless otherwise noted by specimen number: 95, urosternite VII; 96, idem, left lateral comb; 97, idem, right lateral comb; 98, coxites IX, stylets and penis; 99, base of terminal filaments; 100, cerci, most distal surviving divisions; 101, median filament, most distal surviving divisions; 102, coxites VIII and IX of $q$, stylet and ovipositor (WAM E89201); 103, right coxite IX of another paratype (WAM E89199); 104, apex of ovipositor (WAM E89199). All scale bars $=0.1 \mathrm{~mm}$. 
cilia, sixth division similar but longer, seventh division with four rosettes. Most distal surviving division (tenth) (Figure 101) subdivided into five indistinctly defined annuli. A raised ridge is present around the constriction above the macrochaetae in the most distal annulus and at the join between the basal and following annulus of the most distal divisions of both the cerci and median filament.

Female: Similar to male except genital region as in figure 102, the internal process of coxite IX fairly long, about twice as long as wide at its base and about six or seven times longer than the short external process, reaching to about three quarters of the stylet length. Apex of internal process acute on one paratype (WAM E89201) but more rounded in another (WAM E89199) (compare figures 102 and 103) with slightly pectinate macrochaetae along much of the margins, those on the dorsal side of the margin more pectinate than those inserted ventrally. Ovipositor not long (up to 1.6 times HW), only just surpassing the apex of the inner processes of coxites IX, consisting of about 11 divisions; of primary type with numerous short and two very long, thin setae on the last division of the gonapophyses (Figures 102, 104).

\section{ETYMOLOGY}

The species is named from the new Latin adjective aurantius, meaning orange coloured or tawny, referring to the orange-brown of the macrochaetae and especially the posterior segments of the abdomen in alcohol preserved specimens.

\section{HABITAT}

Almost 150 specimens of this species were collected, almost always in pitfall traps, with only one being collected using Winkler sack litter sampling and four individuals collected by suction sampling at a

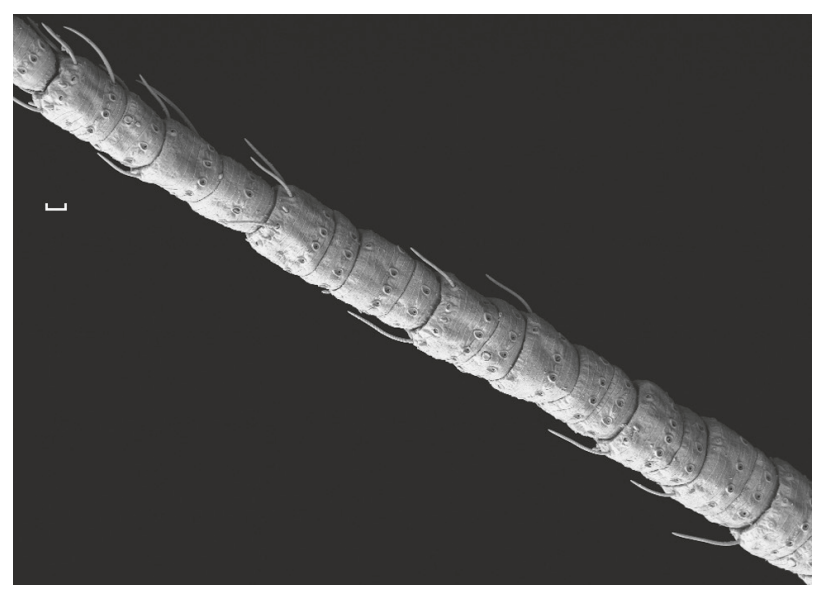

FIGURE 105 Qantelsella aurantia sp. nov. distal intervals of antennae. Scale bar $=0.01 \mathrm{~mm}$ single site. They were collected from a wide variety of habitats on the island from ridge tops to the edge of beaches including also disturbed habitats such as around the current airport. The largest numbers appear to be found habitats such as coastal dunes, floodplains and valley flats.

\section{DISCUSSION}

These two species are placed within the recently described genus Qantelsella Smith, with some hesitation. In comparison to the Australian species of Acrotelsella, they all share a reduction in cephalic chaetotaxy with fewer macrochaetae on the anterior of the frons. However, the Somalian and Arabian species of Acrotelsella also show a divergence from this pattern. The disappearance of the submarginal group of macrochaetae behind the antennae in Australian Acrotelsella species is also notable (compare with Figure 107). The long thin seta associated with this group is found on its own, much closer to the margin in species of Qantelsella. There is only a single row of macrochaetae in the pronotal collar, combs of more than one macrochaeta are restricted to the anterior half of the nota. The posterior $1+1$ combs consist of only a single macrochaeta. The dorsal abdominal chaetotaxy is reduced to $2+2$ combs on urotergites II-VII. On the more distal antennal intervals all have circular sensillae, presumably poculiform (but this has not been confirmed in $Q$. maculosa and $Q$. louisae due to insufficient material being available for electron microscopy). These are generally considered absent in Acrotelsella, but this may reflect the inadequate knowledge of the genus. Circular sensillae could not be found in electron micrographs of one undescribed Acrotelsella species from north-western Victoria but are reported in the following species which is tentatively placed within Acrotelsella. All three Qantelsella species

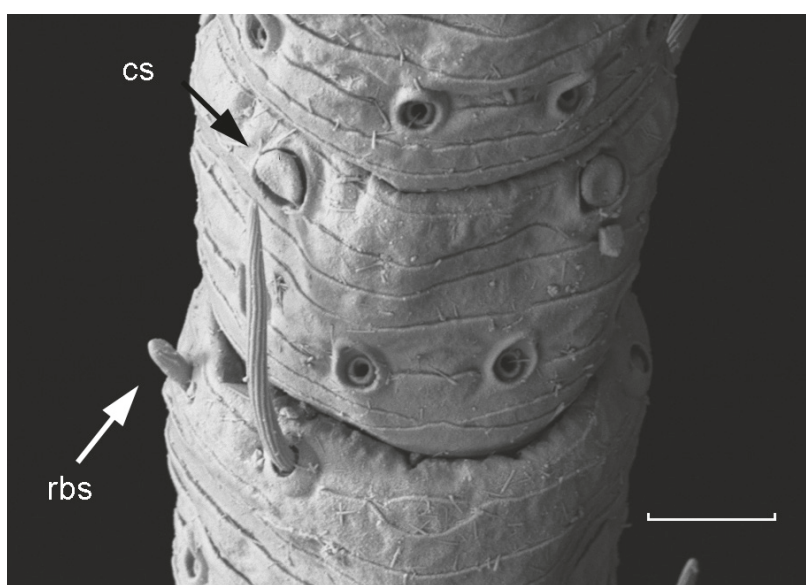

FIGURE 106 Qantelsella aurantia sp. nov: idem, rod-shaped basiconic sensilla (rbs) and circular sensilla (cs). Scale bar $=0.01 \mathrm{~mm}$. 
Acrotelsella Silvestri, 1935

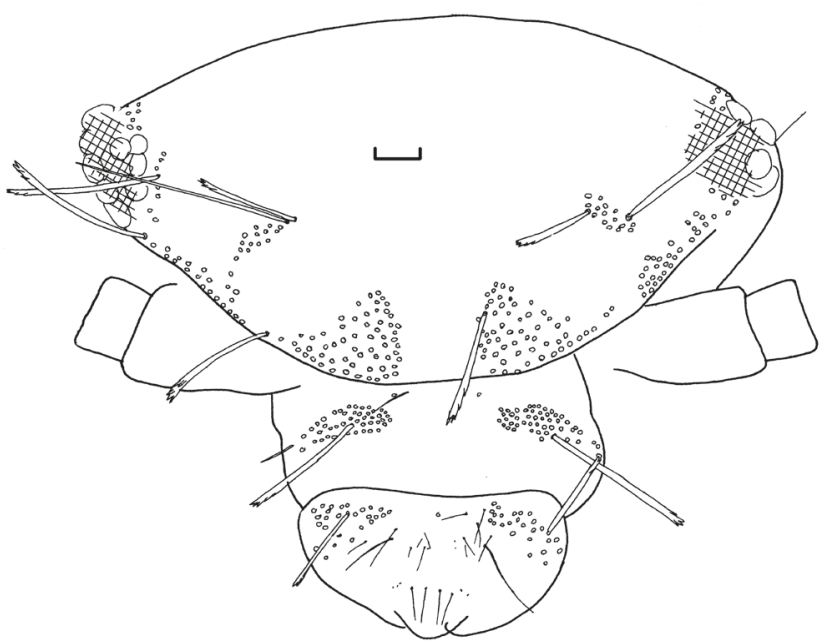

FIGURE 107 Acrotelsella sp. Barrow Island: head. Scale bar $=0.1 \mathrm{~mm}$.

share a markedly rounded, subtriangular urotergite $\mathrm{X}$ which lacks combs but has very dense marginal setae, with those protruding from the lower face of the margin being very pectinate, almost plumose.

However, there are some quite significant differences between the three species of Qantelsella. The chaetotaxy of the clypeus and labrum can consist of either weak bushes or distinct combs (always bushes and often very dense in Australian Acrotelsella), the papillae on the labial palps appear to be either of the compact or aufgelöst type. The shape and chaetotaxy of the thoracic sterna can be quite variable, from trapezoidal to cordiform, with multiple lateral combs to glabrous. Stylets can be present in one or two pairs and scales may be present or absent on the terminal filaments.

A key to the described species of the genus Qantelsella is given below.

1. Stylets present only on segment IX; thoracic sterna all rounded; distinct orange tawny colour to macrochaetae and posterior abdominal segments Q. aurantia sp. nov.

Stylets present in two pairs; some or all thoracic sterna trapezoidal

2. All thoracic sterna trapezoidal with $1+1$ posterior combs; terminal filaments not distinctly banded; scales present on basal divisions of terminal filaments Q. louisae Smith, 2015

Metasternum glabrous with round posterior margin; terminal filaments distinctly banded; scales absent from terminal filaments.

.. . maculosa sp. nov.
Stylifera Stach, 1932: 333, 345 pro parte.

Acrotelsella Silvestri, 1935: 307.

\section{TYPE SPECIES}

Acrotelsa producta Escherich, 1905 by original designation.

\section{Acrotelsella transpectinata sp. nov.}

http://zoobank.org/NomenclaturalActs/B01B03C26355-4E6C-9275-92DBD8846143

Figures 108-160

\section{MATERIAL EXAMINED}

\section{Holotype}

Australia: Western Australia: ô (HW 1.39), Barrow Island, site GP6 (337733, 7700903), 15 March 2006, S. Callan, R. Graham, PIT (WAM E89211) on two slides.

\section{Paratypes}

Australia: Western Australia: $\delta$ (HW 1.29), same data as holotype (WAM E89212) in ethanol; o (HW 1.35), same data as holotype (WAM E89213) in ethanol; $\widehat{\delta}$ (HW 1.33), same data as holotype (WAM E89214) in alcohol; $\widehat{\partial}$ (HW 1.28), Barrow Island, site CC2 (337659, 7697280), 15 March 2006, S. Callan, R. Graham, PIT (WAM E89215) in alcohol; ô (HW 1.18), Barrow Island, site GP7 (337722, 7699467), 15 March 2006, S. Callan, R. Graham, PIT (WAM E89216) in alcohol; ㅇ (HW 1.14), Barrow Island, site GP5 (338740, 7701088), 15 March 2006, S. Callan, R. Graham, PIT (WAM E89217) in alcohol; + (HW 1.18), same data as previous, PIT (WAM E89218) in alcohol; $\widehat{o}$ (HW 1.18), same data as previous (WAM E89219) on two slides; $\hat{\sigma}$ (HW 1.13), same data as previous (WAM E89220) in alcohol (in two

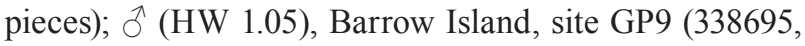
7699237), 15 March 2006, S. Callan, R. Graham, PIT (WAM E89221) in alcohol; ㅇ (HW 1.15), same data as previous (WAM E89222) on two slides; $\widehat{\delta}$ (HW 1.31), Barrow Island, N13 (332808, 7694467), 15 March 2006, S. Callan, R. Graham, PIT (WAM E89223) in alcohol.

\section{Other material examined in detail but not included in types series:}

Australia: Western Australia: $\hat{\partial}$ (HW 1.31), Barrow Island, site GP4 (339635, 7700983), 15 March 2006, S. Callan, R. Graham, PIT (AMS) used for electron microscopy; sex unknown (HW 1.03), Barrow Island, site CC2 (337659, 7697280), 15 March 2006, S. Callan, R. Graham, PIT (AMS K261098) on one slide (incomplete specimen, lacking abdominal segments VIII-X); $\widehat{o}$ (HW unknown), same data as previous, (AMS K261099) on one slide (abdominal segments 

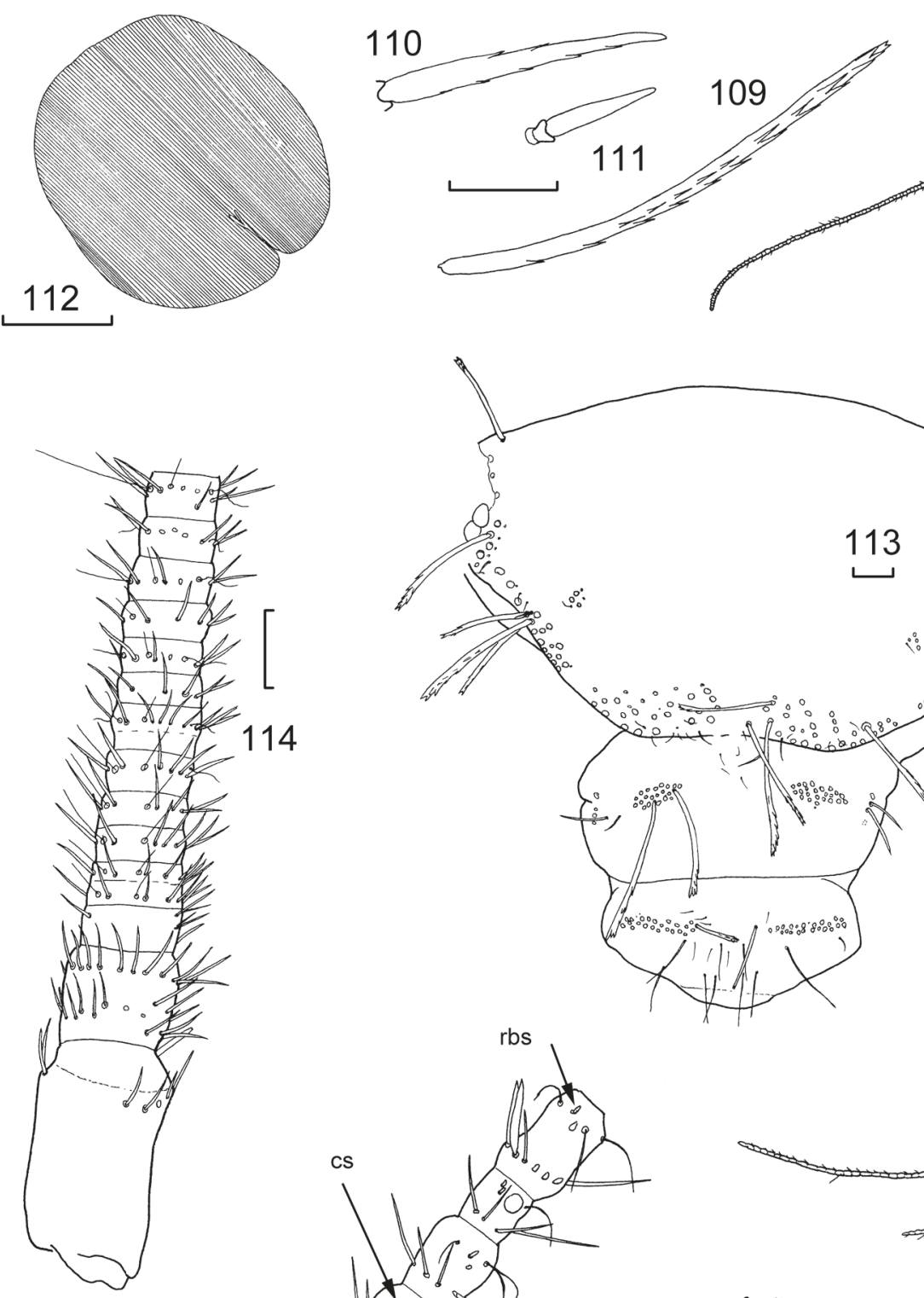

114
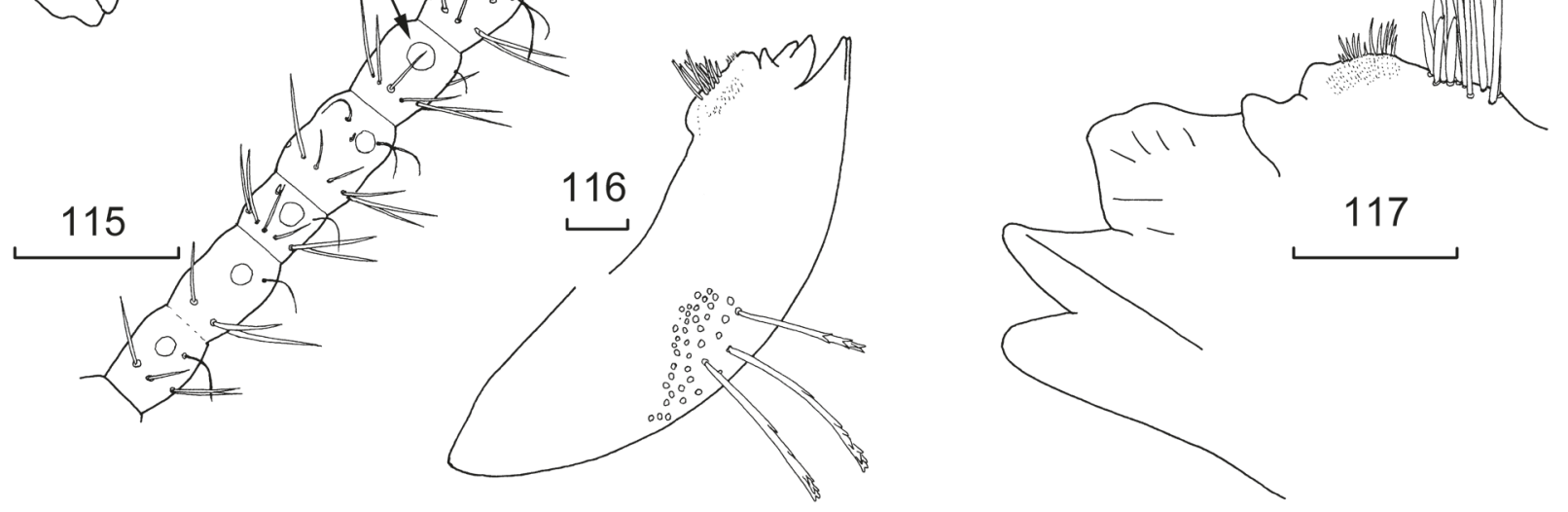

FIGURES 108-117 Acrotelsella transpectinata sp. nov., holotype male (WAM E89211): 108, habitus; 109, lateral macrochaeta of mesonotum; 110, macrochaeta from tibia; 111, smooth macrochaeta from basal tarsal article; 112, darker scale from nota; 113, head (cross-hatched area obscured by eye pigment); 114, antenna, scape, pedicel and basal intervals of flagellum; 115, idem, most distal surviving interval showing rod-like basiconic sensilla (rbs) and circular sensilla (cs); 116, mandible; 117, idem, distal end. Scale bars $=0.1 \mathrm{~mm}$ unless otherwise indicated. 
VIII-X); sex unknown (HW 1.28), same data as previous, (AMS K261100) on one slide (incomplete specimen, lacking abdominal segments VIII-X); ㅇ (HW 0.98), Barrow Island, site N06b (336837, 7699444), 1 May 2007, S. Callan, K. Edwards, PIT (AMS K377611) in alcohol; juvenile (HW 0.73), Barrow Island, N14 (336303, 7698063), 1 May 2007, S. Callan, K. Edwards, PIT (K377612) in alcohol; ठ̊ (HW 0.99), Barrow Island, site GP6 (337733, 7700903), 15 March 2006, S. Callan, R. Graham, PIT (AMS K377613) in alcohol; 今 (HW 1.15), Barrow Island, site GP4 (339635, 7700983), 25 September 2006, S. Callan, R. Graham, PIT (AMS K377614) in alcohol (in two pieces).

\section{DIAGNOSIS}

This species can easily be distinguished from other described Acrotelsella by the presence of transverse combs on coxites IX, the single pair of stylets and the circular (poculiform?) sensillae on the antennae.

\section{DESCRIPTION}

Appearance: Scale pattern when live unknown; in alcohol brown. Middle of the head covered with brown scales, with wide areas of hyaline scales along the sides and front of the head; body with two longitudinal darker stripes along most of the length, more obvious anteriorly, with hyaline scales between the darker stripes and along the sides of the body (Figure 108).

Body size: Medium-sized silverfish with fairly elongate body, medium length antennae and long terminal filaments; thorax only slightly wider than abdominal segment I, the following abdominal segments about the same width until the fifth and only narrowing moderately towards the posterior end. $\mathrm{H}+\mathrm{B}$ up to 9.2 $\mathrm{mm}\left(\right.$ (q), $9.0\left({ }^{\Uparrow}\right)$; maximum head width $1.46 \mathrm{~mm}$; thorax: length up to $2.28 \mathrm{~mm}$ or 0.25 times $\mathrm{H}+\mathrm{B}$ (range 0.22-0.32); width up to $2.0 \mathrm{~mm}$ with no great difference between the pro, meso and metanota although the mesonotum is the widest and the pronotum the narrowest, all nota about the same length; antennae incomplete in most specimens, maximum length of antenna $5.7 \mathrm{~mm}$ or 0.7 times $\mathrm{H}+\mathrm{B}$ (range $0.71-0.78$ ); maximum length of intact cercus $8.15 \mathrm{~mm}$ or $0.86 \mathrm{H}+\mathrm{B}$ (range 0.71-1.02); median dorsal appendage broken in all specimens measured although in some other specimens the median dorsal appendage was almost $1 \frac{1}{2}$ times $\mathrm{H}+\mathrm{B}$.

Pigmentation: Pedicel and scape with faint light brown or slightly orange pigment, denser distally on the pedicel and laterally on the scape; flagellum without pigment. Head and mouthparts largely without pigmentation except for light brown-orange pigment on the last two articles of the maxillary palp, being slightly more intense on the penultimate article. Legs mostly without pigment; some light pigment distally on the outer side of the tibia, more intense dorsally and a little on the tarsi. PII and PIII with some pigment laterally on the distal end of the femur but the last two tarsal articles are without pigment. Stylets without pigment. Terminal filaments not banded, fairly even brown in colour although the colour on the medial filament decreases along its length to be almost absent distally.

Macrochaetae: Pectinate, of variable form (Figures 109-111), mostly hyaline but those of the pronotal collar and some on the tibia are slightly brown.

Scales: With numerous sub-parallel ribs (Figure 112), which can be quite different in their spacing (Figure 156); darker dorsal scales with brown ribs that do not surpass the edge of the scales, hyaline scales with rays further apart; shape of scales generally round, although the ends of the scales can be very straight for those scales on the posterior margins of the tergites and others shaped to fit around setae or combs. Scales found on top of head, on pedicel, all nota, all thoracic sterna, legs except for distal three articles of tarsi, all urotergites and urosternites, stylets IX and on parts of the terminal filaments. The scales of the terminal filaments very diverse in shape including some broader, very irregularly shaped scales as well as some lanceolate scales (Figure 157).

Head: Wider than long (Figure 113, 158), with 1+1 bushes of pectinate macrochaetae on the anterolateral corners not very dense and not aligned in distinct rows. There is a small gap along the margin the above the antennal bases after which there are marginal rows about two to three macrochaetae wide running along the sides of the head to the level of the eyes and then running above the eyes. On each side of the head there is also a small isolated group of macrochaetae posterior to the antennal bases. Clypeus with $1+1$ bushes of about 20-25 macrochaetae as well as some curved setae laterally. Labrum also with $1+1$ bushes of pectinate macrochaetae as well as many simple setae and two longer thin setae. Eyes dark brown with 12 ommatidia (Figure 158). Antennae incomplete in all specimens but fairly long, reaching about three quarters $\mathrm{H}+\mathrm{B}$. Scape (Figure 114) quite long with scales over surface and short robust simple setae pre-apically, pedicel with scattered setae over face and a pre-apical rosette of simple setae, first interval/annulus of flagellum with a few simple setae, subsequent intervals with single rosette of setae transversely across the middle of the interval and two short trichobothria per interval, and, from about the fifth interval, some long curled cilia. Intervals further divide from the sixth with the trichobothria only in the most distal annulus; the trichobothria becoming longer from about the ninth interval, after which the intervals further divide to give four annuli per interval. Circular (poculiform?) sensillae appearing on some annuli from the 12th interval (Figures 159, 160). Intervals fully subdivided into eight annuli by the seventeenth interval. More apical intervals (Figure 115) with eight annuli, the T-annulus with wider setae than other annuli as well as some rod-like basiconic sensillae and some fine pre-apical cilia; the 


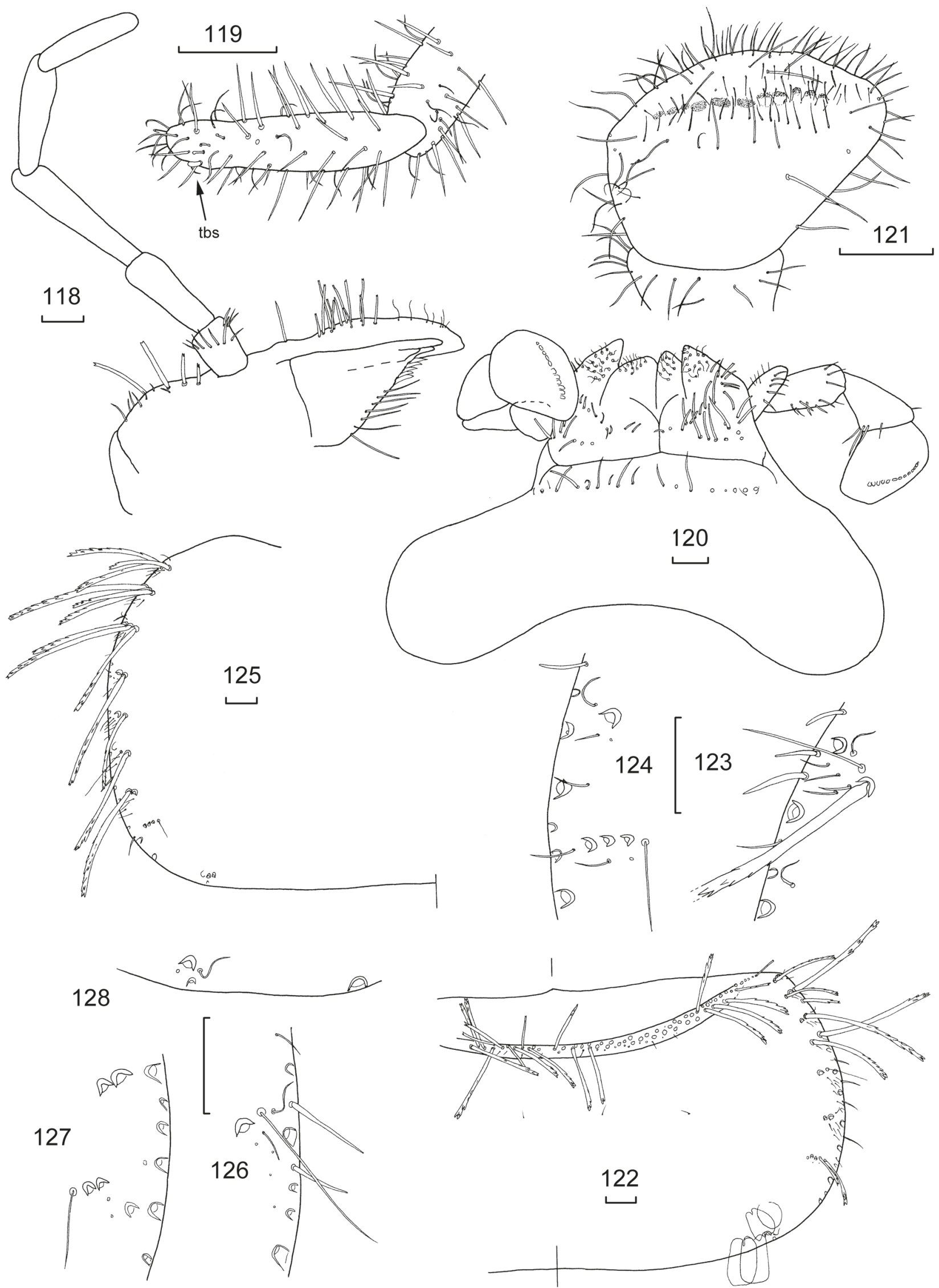

FIGURES 118-128 Acrotelsella transpectinata sp. nov., holotype male (WAM E89211): 118, maxilla; 119, idem, ultimate article of palp showing thin-walled basiconic sensilla (tbs); 120, labium; 121, idem, ultimate article of palp; 122, pronotum, right half; 123, idem, left anterior trichobothrial area; 124, idem, left posterior trichobothrial area; 125, mesonotum, left side; 126, idem, right anterior trichobothrial area; 127, idem, right posterior trichobothrial area; 128, idem, right posterior comb. All scale bars $=0.1 \mathrm{~mm}$. 


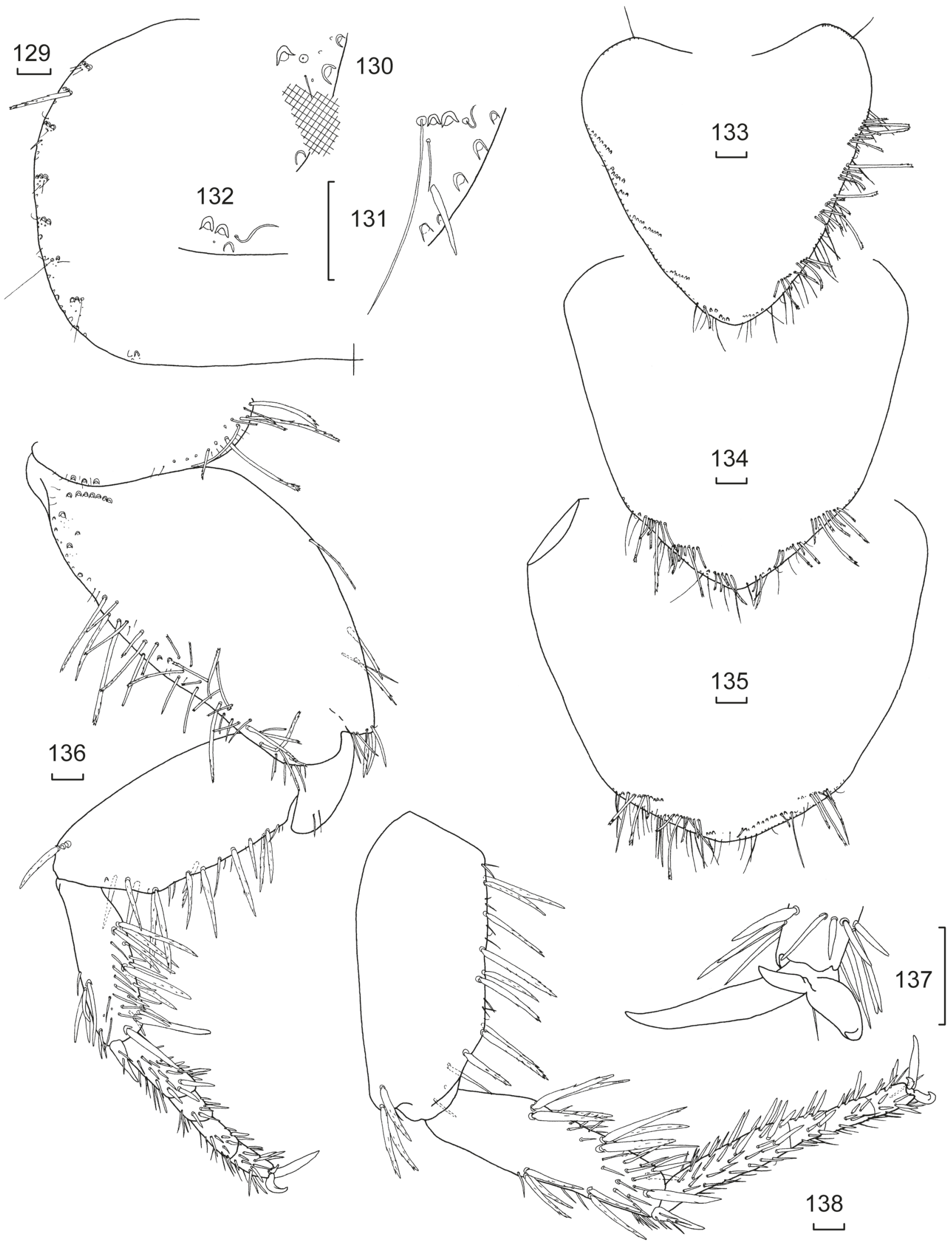

FIGURES 129-138 Acrotelsella transpectinata sp. nov., holotype male (WAM E89211): 129, metanotum, left half; 130, idem, right anterior trichobothrial area (cross-hatched area obscured by dirt); 131, idem, right posterior trichobothrial area; 132, idem, right posterior comb; 133, prosternum; 134, mesosternum; 135, metasternum; 136, PI, smaller setae omitted; 137, pretarsus; 138, PII (smaller setae omitted). All scale bars $=0.1 \mathrm{~mm}$. 
distribution of the sensillae needs to be confirmed but in the holotype the basal five and penultimate annuli of an interval with circular (poculiform?) sensillae. Mandibles (Figures 116, 117) typical for Acrotelsella with well-developed molar and incisor areas; a group of about nine to ten strong apically bifurcated but simple setae distally adjacent to the pectinate molar area and a bush of about 40 pectinate macrochaetae externally. Maxilla (Figure 118) with some thick apically bifurcate but otherwise smooth macrochaetae externally proximal to the palp, the lacinia with three strong teeth, one set further back than the other two, followed by about five lamellate processes and a row of seven thin simple setae, galea with about 13 strong, smooth, apically bifurcate setae externally in its basal half and a few cilia distally; apical article of maxillary palp (Figure 119) 4.1 times longer than wide (range 3.4-5.2) and 1.1 times longer than penultimate article (range 0.92-1.31), the ultimate article in both sexes with a thin-walled basiconic sensilla subapically (type C of Adel, 1984) and some small rodlike basiconic sensillae near it (type B of Adel, 1984), last four articles of palp with fine setae only, basal article with oblique rosette of slightly thicker setae and a few similar setae on one side subapically. Labium (Figure 120) short and broad, prementum with transverse row of apically bifurcate setae, glossae and paraglossae with transverse and oblique rows of short strong apically bifurcated setae, apically with short curved setulae; labial palp short, apical article expanded medially (Figure 121), 1.1 times wider long (range 0.80-1.43) with row of 11-12 (?) papillae of compact type arranged in a single row, apparently without sensillae on the outer margin, covered with numerous fine short setae as well as longer fine setae on along the distal end.

Thorax: Pronotum (Figure 122) with narrow setal collar about two macrochaetae wide composed of similar length macrochaetae as well as some small cilia; lateral margins with a few setae along the margin, with a comb of two pectinate macrochaetae at the anterior corner followed by seven combs of one to four pectinate macrochaetae evenly spaced along the anterior three quarters of the notum, the combs associated with one to six setulae posterior to the comb. Two open trichobothrial areas; the anterior area (Figure 123) is slightly forward of the midpoint and associated with the fifth comb with its trichobothrium located between the comb of a single macrochaeta and the macrochaeta on the margin. Posterior trichobothrial area (Figure 124) around three quarters of the distance along the margin and associated with the last comb of three to four, somewhat smaller, pectinate macrochaetae, its trichobothrium located at the mediad end of the comb. Both areas have a few setulae posterior to the comb. Posterior margin with $1+1$ single macrochaetae each associated with a marginal seta and a cilium, the posterior combs being positioned quite laterally.
Mesonotum (Figure 125) with lateral chaetotaxy similar to pronotum with eight combs of one to three pectinate macrochaetae, the anterior trichobothrial area (Figure 126) located about two thirds the way along the lateral margin associated with the sixth comb of just one macrochaeta with the trichobothria located between the macrochaeta and the margin, with a few setulae posterior to the comb and a cilium between the trichobothrium and the margin. Posterior trichobothrial area (Figure 127) slightly more posterior than that on the pronotum, the trichobothria located mediad to eighth comb of two to three weaker pectinate macrochaetae and a couple of setulae posterior to the comb. Posterior margin with quite laterad $1+1$ combs (Figure 128) of one or two macrochaetae with a cilium at the outer end, a marginal seta and perhaps a setula between the comb and the margin similar to that of pronotum. Metanotum (Figures 129-132) similar to mesonotum but with only seven combs of one to three macrochaetae, the anterior trichobothrial area associated with the sixth comb of just one macrochaeta about two thirds the distance along the margin, the posterior trichobothrial area associated with the following comb and the posterior $1+1$ combs again quite laterad with one or two macrochaetae, a laterad cilium, a marginal seta and a setula.

Presternum narrow, with transverse row of long macrochaetae. All thoracic sterna with hyaline scales. Prosternum (Figure 133) large, about as long as wide at its base, rounded apically, anterolateral corners with fringe of fine simple setae, posterior three quarters of lateral margins with long fine simple setae and some cilia as well as six to eight short combs of three to eight pectinate macrochaetae on each side as illustrated. Mesosternum (Figure 134) a little larger than prosternum and slightly more acute apically, but also about as long as wide at its base, with long, thin simple marginal setae and $3+3$ combs in its distal third, composed of three to eight shorter and longer pectinate macrochaetae. Metasternum (Figure 135) apically rounded, about 1.25 times wider than long with marginal setae and cilia along distal quarter of lateral margins and $3+3$ combs of longer and shorter pectinate macrochaetae but the macrochaeta at one or both ends of the combs are simple not pectinate; the most distal comb may almost merge with the adjacent comb.

Legs quite long and slender, tibia $\mathrm{L} / \mathrm{W}$ ratio of legs PI 2.9 (range 1.66-5.71), PII 3.6 (2.88-4.87), PIII 4.4 (3.71-5.33); tarsi L/W ratio PI 5.6 (range 5.07-6.80), PII 7.3 (5.44-8.50), PIII 11.0 (8.29-12.67). PI (Figure 136) with transverse comb of three macrochaetae laterally on precoxa. Coxa with scales and a comb of about seven macrochaetae on the anterolateral corners followed by many strong pectinate macrochaetae along the external margin; inner margin with a few finer macrochaetae and about seven setae of varying thickness distally 

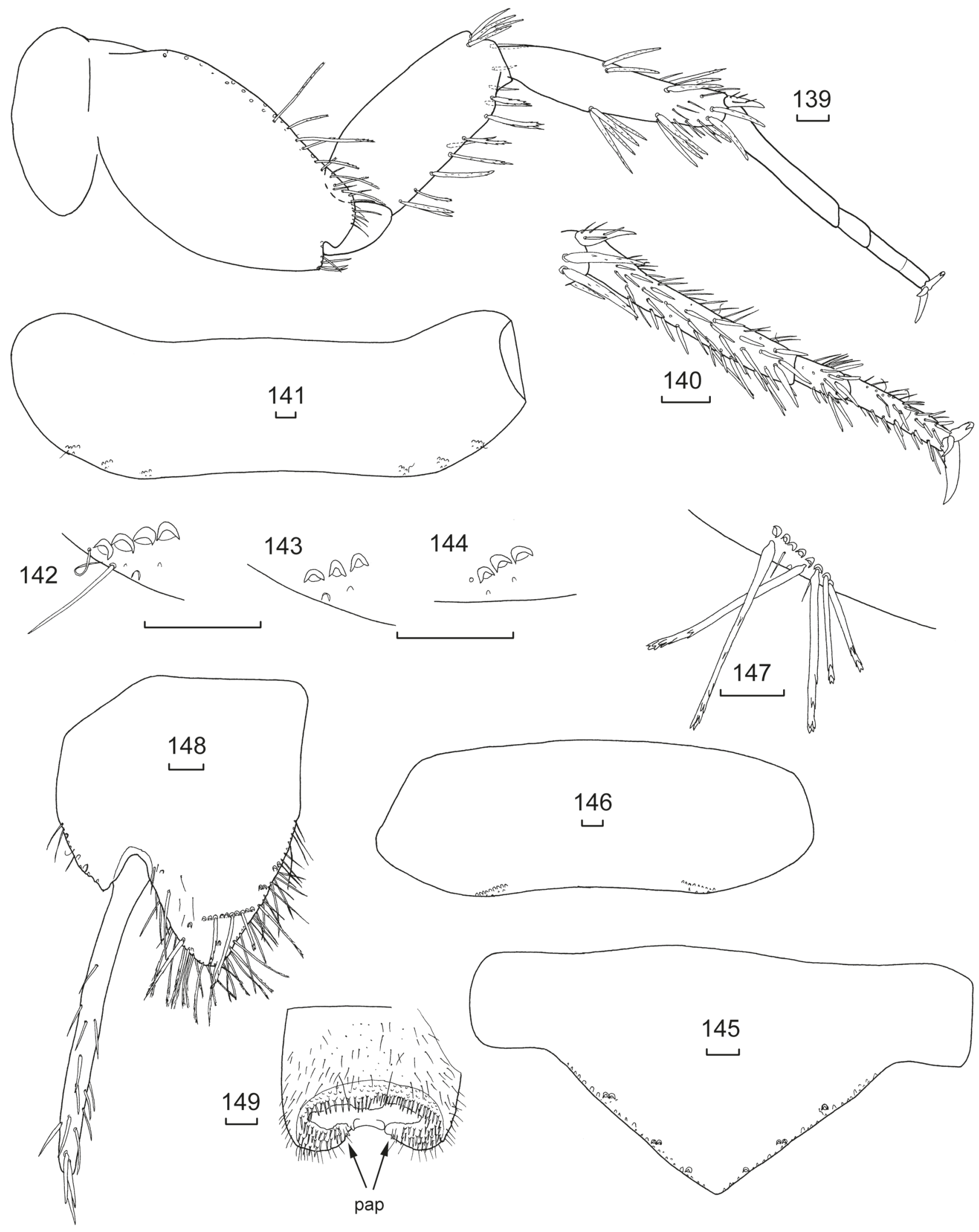

FIGURES 139-149 Acrotelsella transpectinata sp. nov., holotype male (WAM E89211): 139, PIII, smaller setae omitted and all setae from tarsus also omitted; 140, idem, tarsus; 141, urotergite II; 142, idem, left lateral comb; 143, idem, left sublateral comb; 144, idem, left submedial comb; 145, urotergite X; 146, urosternite $\mathrm{VI}$; 147, left lateral comb of urosternite IV; 148, right coxite IX and stylet, with smaller setae of stylet omitted; 149, penis, showing papillae (pap). All scale bars $=0.1 \mathrm{~mm}$. 
over the articulation. Trochanter with a few scales. Femur ventrally with several strong, thick pectinate macrochaetae and dorsally with three pectinate macrochaetae in addition to fine setae scattered over the mediad one third of the dorsal surface. Tibia of PI with numerous stout, carrot-shaped, slightly pectinate macrochaetae along most of the ventral margin and a submarginal row of shorter stout, rounded setae parallel to the margin; dorsal surface with group of stout setae about two thirds of the distance along the margin; apex of tibia with two stout pectinate macrochaetae and the usual apical spur which has some stout, rounded setae. Tarsi with four articles, the basal article of PI about $40 \%$ of the total length of the tarsus, its join with the next article not particularly oblique, the ventral face of all tarsal articles with rounded, stout setae which are longer near the apex of each article, dorsally with some simple setae. Pretarsus with two very long curved lateral claws and a much shorter curved medial claw (Figure 137). PII (Figure 138) and PIII (Figure 139) similar to PI except lacking the anterolateral comb on the coxa; legs progressively longer from anterior to posterior and the relative length of the basal tarsal article is progressively longer, being about $60 \%$ of the total length on PIII (Figure 140).

Abdomen: Urotergite I with 1+1 lateral combs of three to four macrochaetae each associated with one marginal seta, two to three setulae and a cilium at the laterad end of the comb, urotergites II-VII (Figure 141) with 3+3 combs of macrochaetae as in table 3 , the lateral combs (Figure 142) also associated with 0-2 marginal setae, 1-7 setulae and one or two cilia, almost always at the laterad end of the comb but occasionally at both ends, the sublateral combs (Figure 143) usually associated with one to four setulae, occasionally a marginal seta but lacking cilia, the submedial combs (Figure 144) associated with none or one marginal seta, up to four

TABLE 3 Number of macrochaetae per bristlecomb Acrotelsella transpectinata sp. nov.

\begin{tabular}{|c|c|c|c|c|}
\hline \multirow[b]{2}{*}{ Segment } & \multicolumn{3}{|c|}{ Urotergite } & \multirow[b]{2}{*}{ Urosternite } \\
\hline & Lateral & Sublateral & Submedial & \\
\hline I & $3-4$ & - & - & - \\
\hline II & $3-4$ & 3 & $2-3$ & - \\
\hline III & $3-4$ & 3 & $2-3$ & $3-7$ \\
\hline IV & $3-5$ & $3-4$ & $2-3$ & $3-8$ \\
\hline $\mathrm{V}$ & $5-6$ & $2-4$ & $1-3$ & $4-8$ \\
\hline VI & $5-6$ & 4 & $2-3$ & $4-9$ \\
\hline VII & $5-7$ & 4 & $2-3$ & $5-8$ \\
\hline VIII & $5-9$ & - & $2-3$ & $9-11$ \\
\hline IX & - & - & - & $9-10$ \\
\hline
\end{tabular}

setulae and with a cilium at the laterad end of the comb.

Urotergite VIII with 2+2 combs, lacking the sublateral comb; urotergite IX glabrous. Urotergite X (Figure 145) obtusely triangular, in $\widehat{\sigma}$ holotype, wider than long (L/W at base about 0.35 ) with many setae along entire margin, and $3+3$ combs with one or two macrochaetae per comb as well as a few setulae posterior to the combs.

Urosternite I and II glabrous, urosternites III-VII with $1+1$ lateral combs of six to eleven pectinate macrochaetae (Figures 146, 147) each usually associated with a small marginal seta and two to six setulae and rarely a cilium at the laterad end of a comb. The distance between the lateral combs 3.0-8.7 times the average width of these combs, the ratio being largest on urosternite III and decreasing posteriorly.

Each coxite IX (Figure 148) in male with obvious transverse comb of nine to ten macrochaetae across the inner process as well as a smaller comb of two to three macrochaetae on the inner margin and two more macrochaetae further anterior along the medial margin; the internal process in the male neither acute nor elongated, about three times longer than the external process but only 0.8 times as long as broad at its base; external and internal margins of internal process and external margin of outer process with many long, thin, often pectinate setae. Outer process small, triangular with a few setae along the outer margin. Only one pair of long slender stylets (Figure 148) present (on IX) in both sexes; each stylet with three short robust macrochaetae apically. Stylets IX in male holotype (excluding the apical macrochaetae) about three times the length of the internal process. Penis typical with numerous glandular setae apically, each set on a protuberance; with a small three- or four-armed papilla located on either side of opening (Figure 149). Parameres absent.

Cerci (Figures 150, 151) with four basal divisions shorter than wide, then progressively longer, with setae, macrochaetae and trichobothria becoming increasingly stronger and longer distally, divisions from about the seventh subdivided into two annuli and again into four annuli by the ninth and into five by the tenth eventually to eight annuli; scales present in places along entire length of cerci; most distal surviving divisions very long and thin as in figure 151, with setae and cilia but apparently without trichobothria (although these are present along most of the length of the cerci). Median dorsal appendage (Figures 150, 152), first division glabrous, next division with small setae and trichobothria, the setae above simple while those below are pectinate, following division also short with setae and trichobothria in increasing numbers, scales visible at sides on the surfaces proximad to each rosette of chaetotaxy from the fifth division to about the twelfth division after which they are rare but still occasionally found along the length of the remaining appendage (Figure 157), divisions begin to subdivide into two 


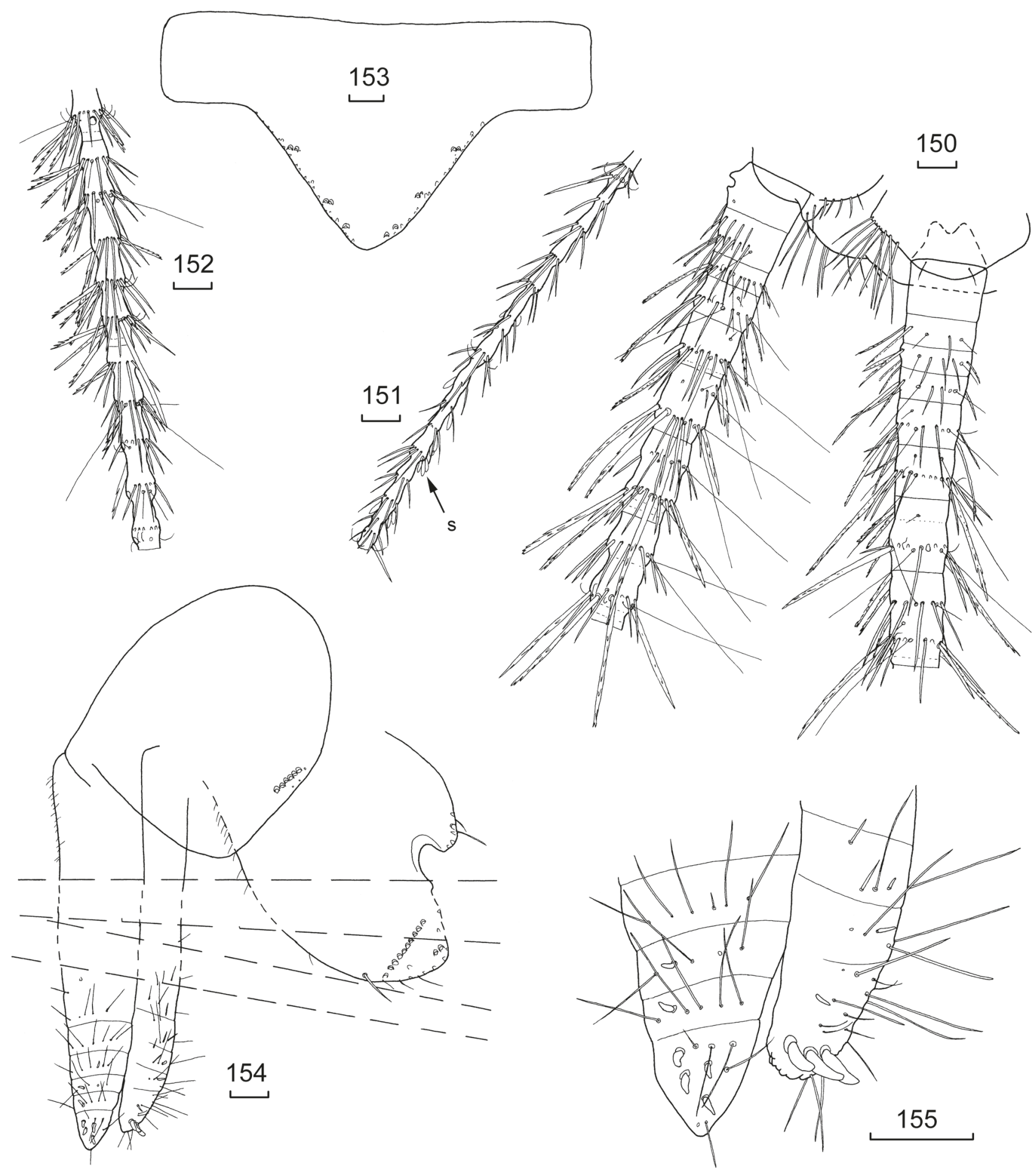

FIGURES 150-152

Acrotelsella transpectinata sp. nov., holotype male (WAM E89211): 150, base of cerci and median dorsal appendage; 151, most distal surviving divisions of cercus, showing some scales (s); 152, most distal surviving divisions of median dorsal appendage. coxites VIII and IX and anterior and posterior valves of ovipositor; 155, idem, detail of apices of gonapophyses. All scale bars $=0.1 \mathrm{~mm}$. 


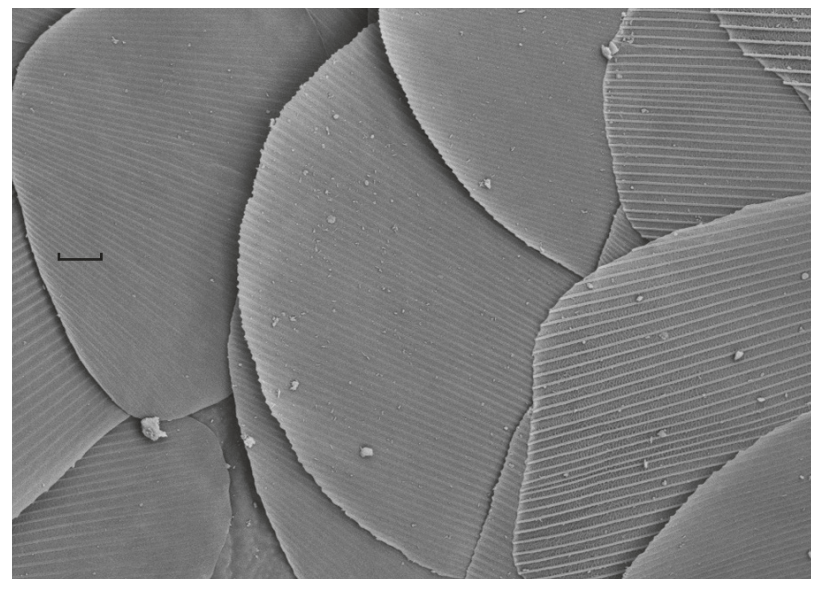

FIGURE 156 Acrotelsella transpectinata sp. nov: scales of urotergites, showing large differences in spacing of ribs. Scale bar $0.01 \mathrm{~mm}$.

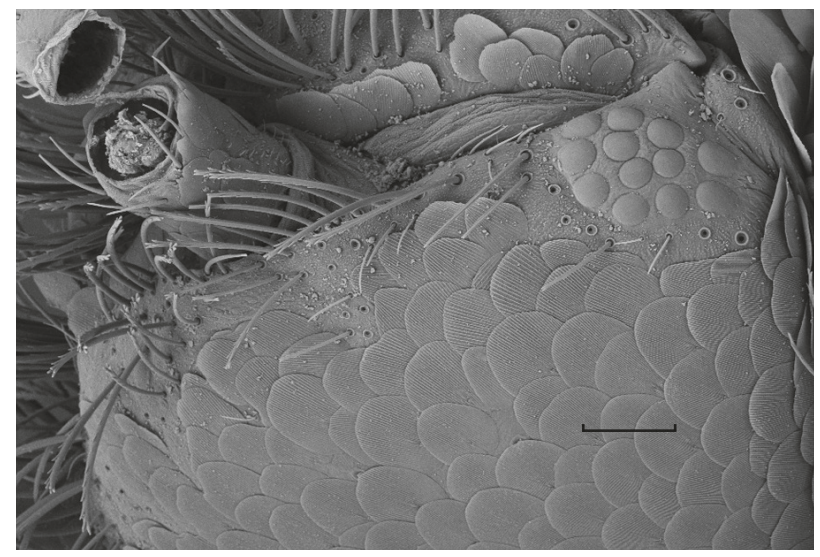
top of head. Scale bar $0.1 \mathrm{~mm}$.

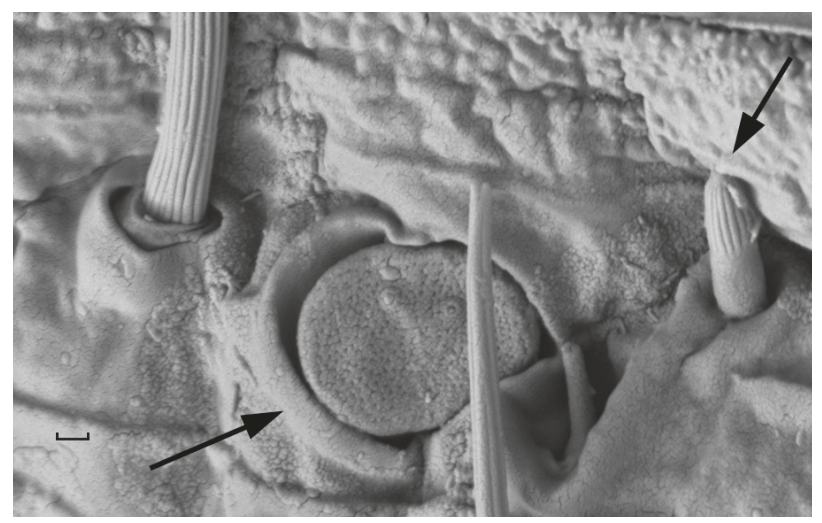

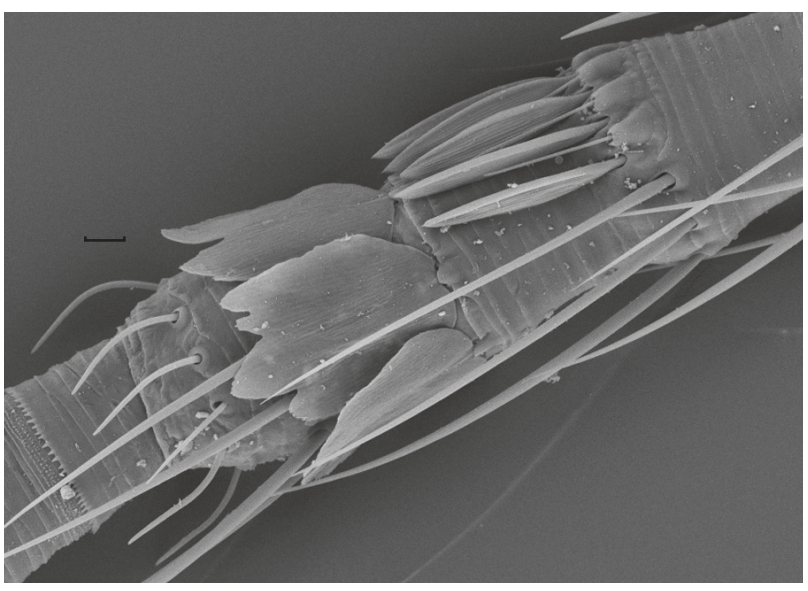

FIGURE 157 Acrotelsella transpectinata sp. nov.: scales on cerci. Scale bar $0.01 \mathrm{~mm}$.

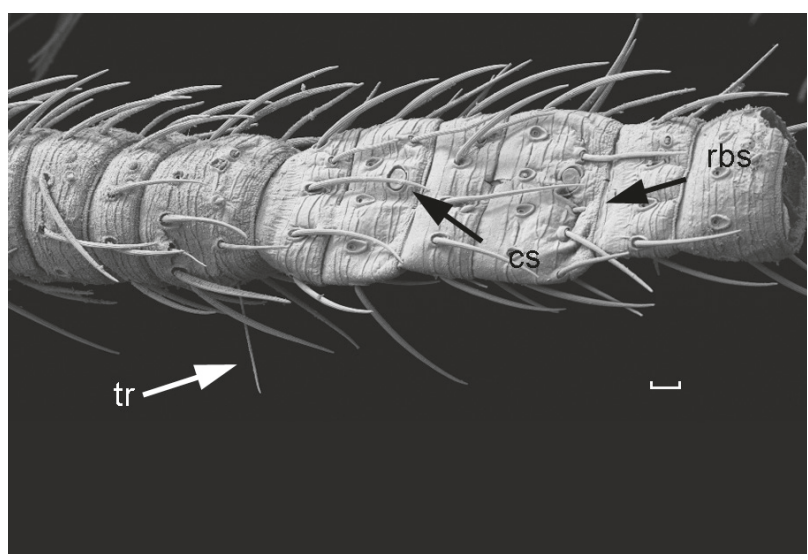

FIGURE 159

Acrotelsella transpectinata sp. nov.: most apical surviving intervals of antenna showing the trichobothrium (tr) on T-annulus, a circular sensilla (cs) and a rod-like basiconic sensillae (rbs). Scale bar $=0.01 \mathrm{~mm}$.
FIGURE 160 Acrotelsella transpectinata sp. nov.: circular (poculiform?) sensilla (left arrow) and rod-like basiconic sensilla (right arrow). Scale bar $=0.001 \mathrm{~mm}$. 
annuli by about the seventh division, and further into four divisions at about the ninth and into five annuli by the eleventh division (Figure 152).

Female: Similar to male except urotergite $\mathrm{X}$ more equilaterally triangular (L/W 0.56 ) also with $3+3$ combs of 1-2 macrochaetae (Figure 153). Genital region of female as in figure 154, the internal process of coxite IX short, about two thirds as long as wide at its base and only four times longer than the rounded external process, almost as long as the ovipositor. Apex of internal process rounded with macrochaetae along much of the margins, a distinct transverse comb present as in the male. Ovipositor short (up to $0.9 \mathrm{HW}$ ), only just reaching the apex of the short internal processes of coxites IX, both pairs of gonapophyses consisting of a long basal divisions (about half the length of the ovipositor), and seven or eight smaller divisions (Figure 154); of secondary type with three modified spines on the last division of the posterior gonapophyses and four on the last division of the anterior gonapophyses (Figure 155), also with long fine setae.

\section{ETYMOLOGY}

The species is named for the transverse comb on coxites IX, a character not previously recorded for species of Acrotelsella.

\section{HABITAT}

More than 170 specimens were collected and all were taken in pitfall traps and were absent from leaf litter. This suggests that they are a quite mobile species as further indicated by its long legs. They therefore probably hide under rocks, or in other cracks in the soil. They were collected in a range of habitats including both valley flats and on limestone ridges and from both natural habitats and those with a history of human disturbance.

\section{DISCUSSION}

The species is placed within the genus Acrotelsella with some hesitation. While it has notal and abdominal chaetotaxy typical of Acrotelsella (apart from the transverse combs on coxites IX), it only carries a single pair of stylets in both sexes. Perhaps more critically, it has a reduced anterior chaetotaxy on the frons and the distal intervals of the antennae have circular (poculiform?) sensillae, characters seen in Qantelsella. Species of Acrotelsella are very common in Australia and quite diverse, with many specimens of undescribed species collected by the author, as well others in various Australian museum collections. It is quite widespread with species being described from the Afrotropical, Australian, Neotropical and Oriental Regions and also found on several oceanic islands (e.g. Hawaii, Seychelles). Our understanding of it, especially with regards to the details of antennal sensillae etc is incomplete and a detailed examination of the morphology of this quite large genus is required.
Subfamily Lepismatinae Latreille, 1802

Lepismenae Latreille, 1802: 70 pro parte.

\section{Xenolepisma Mendes, 1981}

Asterolepisma (Xenolepisma) Mendes, 1981: 200.

Xenolepisma Mendes, 1988: 12.

\section{TYPE SPECIES}

Lepisma globosa Escherich, 1905, by original designation.

\section{Xenolepisma perexiguum sp. nov.}

http://zoobank.org/NomenclaturalActs/801DCA7BE983-4766-8BA7-6E95381D9EE5

Figures 161-191

\section{MATERIAL EXAMINED}

\section{Holotype}

Australia: Western Australia: $ᄋ$ (HW 0.48), Barrow Island, site N22 (335631, 7695646), 1 May 2007, S. Callan, K. Edwards, PIT (WAM E89224) on two slides.

N.B. due to the small size of the specimen, attempts to dissect the head were abandoned and the head was mounted more or less entire on the slide. Interpretation of the mouthparts was quite difficult and the head appears somewhat distorted in the illustrations. Furthermore there was some damage to the posterior end of the specimen prior to receiving the specimen, where the tip of stylets IX, part of urotergite $\mathrm{X}$, the terminal appendages and the ovipositor had all been broken or chewed off.

\section{DIAGNOSIS}

This species can easily be distinguished from other described Xenolepisma by its very small size and the complete absence of dorsal chaetotaxy on the nota and urotergites, apart from the $1+1$ infralateral seta on each segment.

\section{DESCRIPTION}

Appearance: Very small silverfish with abdomen tapering strongly posteriorly (Figure 161). Scale pattern when live unknown; in alcohol mottled brown with the dorsal scales darker on the posterior end of each tergite.

Body size: Body length about $2 \mathrm{~mm}$, although it is suspected that the specimen is somewhat contracted; maximum head width difficult to measure as withdrawn under pronotum, about $0.48 \mathrm{~mm}$; thorax: length up to $0.80 \mathrm{~mm}$ or 0.39 times $\mathrm{H}+\mathrm{B}$; width up to $0.93 \mathrm{~mm}$ being widest at the metathorax, the pronotum slightly longer than the meso and metanota combined. Antennae incomplete, maximum surviving length of antenna 
$0.8 \mathrm{~mm}(>0.4$ times $\mathrm{H}+\mathrm{B})$; terminal filaments broken, probably not protruding much beyond the posterior end of the short urotergite X.

Pigmentation: Where present mottled brown. Head with pigment around eyes and anteriorly, clypeus and labrum not very pigmented. Antennae without banding; pedicel and scape without pigment; flagellum without pigment. Mandibles with pigment on outer face. Maxillae with pigment on outer face of stipes, palps missing. Labium with well pigmented glossae; ultimate article of labial palp pigmented over proximal half. PII without obvious markings, other legs missing. Ovipositor and stylets without pigment.

Macrochaetae: Smooth, hyaline, some more robust and apically bifurcate (Figure 162) but all macrochaetae of the dorsal and ventral combs have been lost.

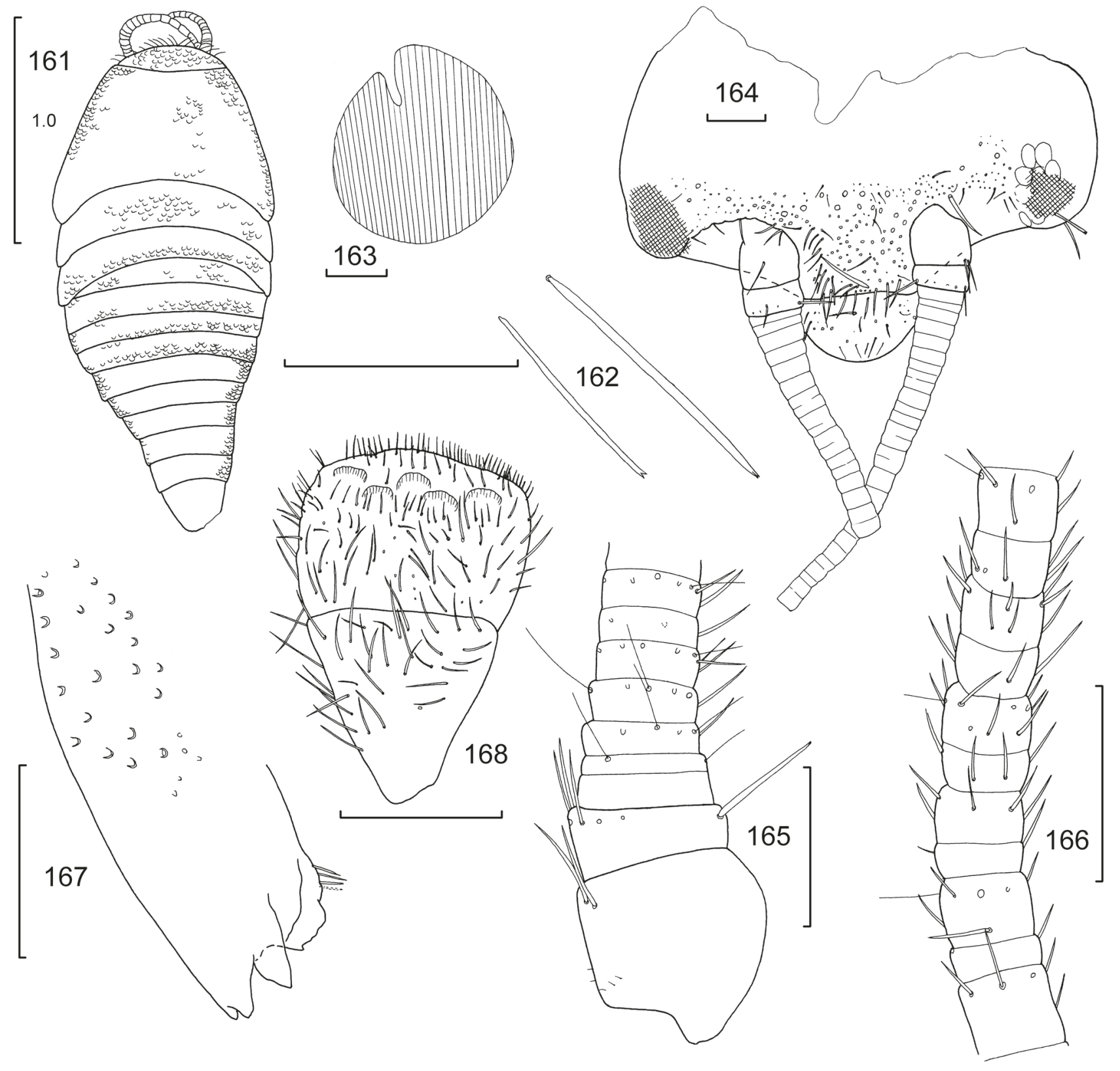

FIGURES 161-168 Xenolepisma perexiguum sp. nov., holotype female (WAM E89224): 161, habitus (N.B. enlarged three times more than habitus drawings of three species described above); 162, macrochaetae of mandible; 163, scale from urotergite; 164, head (cross-hatched area not clear due to eye pigment); 165, antenna, scape, pedicel and basal intervals of flagellum; 166, idem, most distal surviving intervals; 167 , mandible; 168 , ultimate article of labial palp. Scale bars $=0.1 \mathrm{~mm}$ unless otherwise indicated. 
Scales: With sub-parallel rays which do not surpass the posterior margin of the scale (Figure 163), in alcohol mostly dark to lighter brown in colour or hyaline. Scales on top of head but lacking elsewhere on head and absent from mouthparts and antennae, thoracic sterna and coxae scaled, but scales absent from remaining leg articles. Ovipositor and terminal filaments without scales.

Head: Wider than long (Figure 164); eyes very dark, placed well forward; anterior half of frons merges with clypeus without obvious suture; this area (from the level of the eyes forward) is covered with numerous setae, setulae and cilia. Labrum with a few setae in across the mid-line. Antennae (Figures 164-166) incomplete (only thirteen intervals remaining), scape and pedicel (Figure 165) quite short, first interval of flagellum with some setae on one side, intervals two to five with setae and two or three trichobothria, intervals six to eight divided into two annuli and intervals nine to eleven further subdivided with the trichobothrium only in the distal annuli. Annuli of most distal surviving intervals as in Figure 166, composed of four annuli with setae and a single trichobothrium near the apex of the T-annulus. Specialised sensillae not visible but the antennae are incomplete, very small and the quality and orientation of the preparation is less than ideal. Mandibles (Figure 167) difficult to observe, with three or four incisor teeth, and a distinct molar region adjacent to a group of four(?) setae, externally with a field of about 40 strong, simple or apically bifurcate macrochaetae. Maxillae very difficult to observe, apparently with three small teeth, one shorter than the others, but the remaining details are not visible; maxillary palps lost. Labium largely obscured in preparation, apical article of palp (Figure 168) 1.4 times wider than longer, with $3+2$ large compact sensory papillae apically; other specialised sensillae not observed.

Thorax: Pronotum (Figure 169) about 1.2 times longer than mesonotum and 1.3 times longer than the metanotum respectively, although in the whole specimen the prothorax appears much longer than the other two due to them been partially covered anteriorly by the posterior margin of the preceding notum but also probably due to uneven contraction; lacking collar of setae along anterior margin. All nota with setae and some setulae along the lateral margins with the most posterior insertion point looking somewhat larger than the others and with one to three short macrochaetae directed laterally in the anterior corners, posterior margin glabrous. All nota with two closed trichobothrial areas (isolated from margins by scales), those of the prothorax located anteriorly and subposteriorly, while those of the meso- (Figure 170) and metanota (Figure 171) are both subposterior. Each trichobothrial area provided with a short trichobothrium and all appear to lack setulae (Figure
172) although in one case there appears that there could be two setula insertions.

Presternum (Figure 173) with posterior marginal row of fine delicate simple setae. All thoracic sterna with hyaline scales. Prosternum (Figures 173, 174) small, subcordiform, slightly wider at its base than long, with several fine marginal setae distally and $1+1$ simple submarginal setae, as well as $4+3$ setae submedially. Mesosternum (Figures 175, 176) only slightly wider than long and about twice the size of the prosternum, with several small marginal setae distally and 1+1 subapical combs of five setae; the distance between the combs being less than the length of each comb. Metasternum (Figures 177, 178) not intact, with only the apical part discernible, with a few marginal setae apically and a single comb of 15 setae extending across the entire width of the apex of the sternum.

Legs all lost except for a single PII (Figure 179) whose tibia $\mathrm{L} / \mathrm{W}$ is 3.4 and tarsi $\mathrm{L} / \mathrm{W}$ 4.8; subcoxa of PI with three long thin simple setae. Coxae of all legs scaled with setae and short apically bifurcate macrochaetae along the external margin. Coxa of PI (Figure 173) with comb of two long, strong apically bifurcate macrochaetae near the anterior lateral margin, coxae of PII and PIII with only single macrochaeta in this position (Figures 179, 177 respectively). Trochanter fairly large with a few fine setae only. Femur with one longer stout and one smaller macrochaeta at medial posterior angle and a row of fine setae along the anterior margin, the ventral face covered with fine setae. Tibia with two(?) short macrochaetae distally on the external margin and another in the anterior quarter of this margin, posterior margin with one stout macrochaeta about two thirds the distance along the margin and the face covered with fine setae. Tarsi consisting of three articles covered with setae, some of the setae near the distal end of the basal article a bit stronger than the others. Pretarsus with two lateral claws and a medial slightly shorter empodial claw.

Abdomen: Urotergites I-IX (Figure 180) with 1+1 infralateral macrochaetae only (all lost but probably small judging from size of insertions) each insertion point associated with a marginal cilium on the outer edge of the insertion point (Figure 181). Urotergite $X$ (Figure 182) trapezoidal, partially damaged, about 0.6 times as long as wide at its base, with several marginal setae and $2+2$ (?) macrochaetae at the rounded corners of the concave posterior margin.

Urosternite I appears to be without combs (partially obscured by tissue) (Figure 183). Urosternite II with a narrow medial comb of five macrochaetae on a small protuberance of the margin (Figures 183, 184). Urosternites III-VII (Figure 183) with 1+1 sublateral combs (Figures 185, 186) each of 3-5 setae sometimes associated with a small cilium at the laterad end and one medial comb (Figures 185, 187) of 5-9 setae, often 

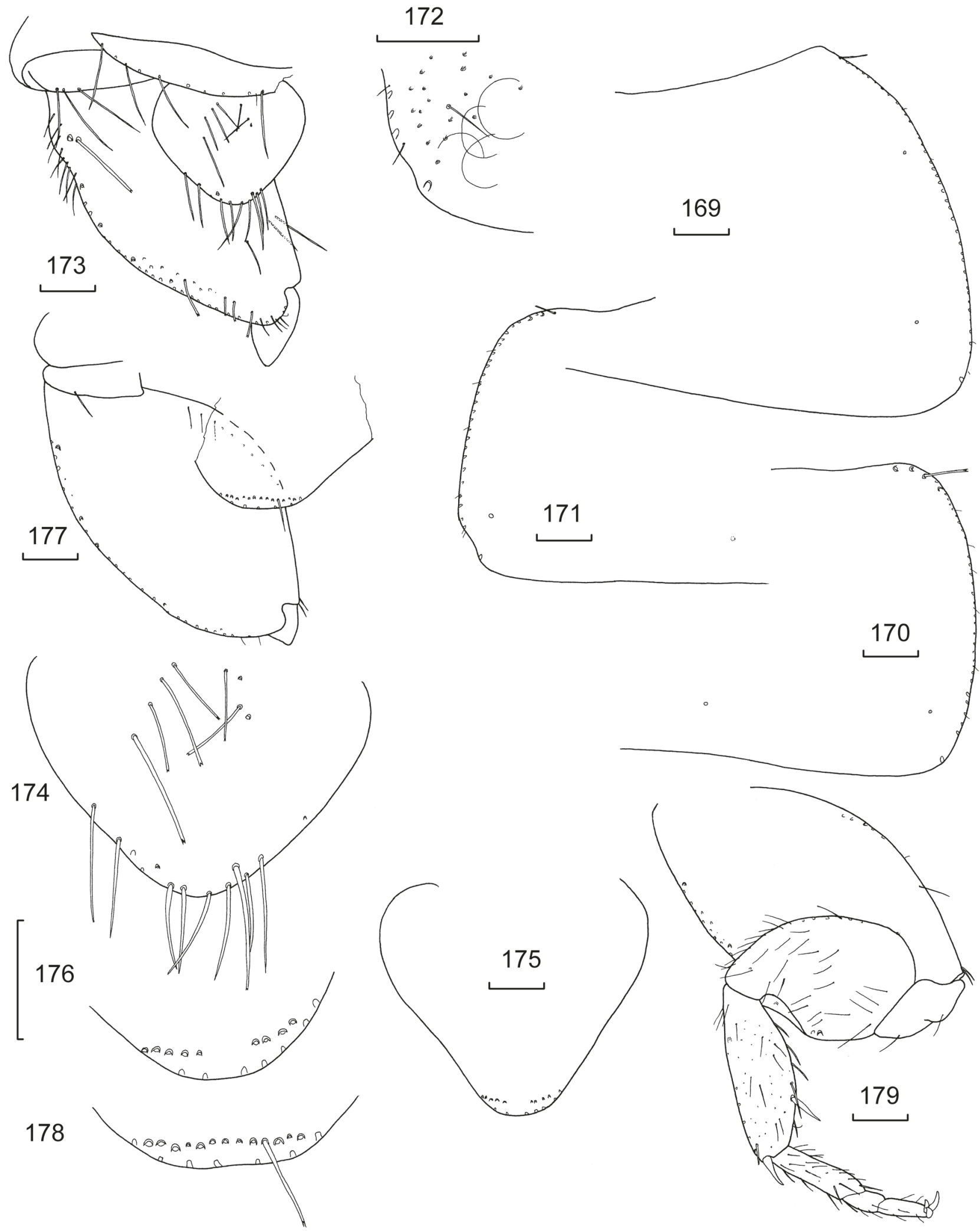

FIGURES 169-179 Xenolepisma perexiguum sp. nov., holotype female (WAM E89224): 169, pronotum, right half; 170, mesonotum, right half; 171, metanotum, left half; 172, idem, lateral trichobothrial area, also showing scale insertions and the outline of some scales; 173, presternum, prosternum, coxa and trochanter of PI; 174, prosternum; 175, mesosternum; 176, idem, enlargement of apex; 177, metasternum and coxa of PIII; 178, detail of apex of metasternum; 179, PII. All scale bars $=0.1 \mathrm{~mm}$. 

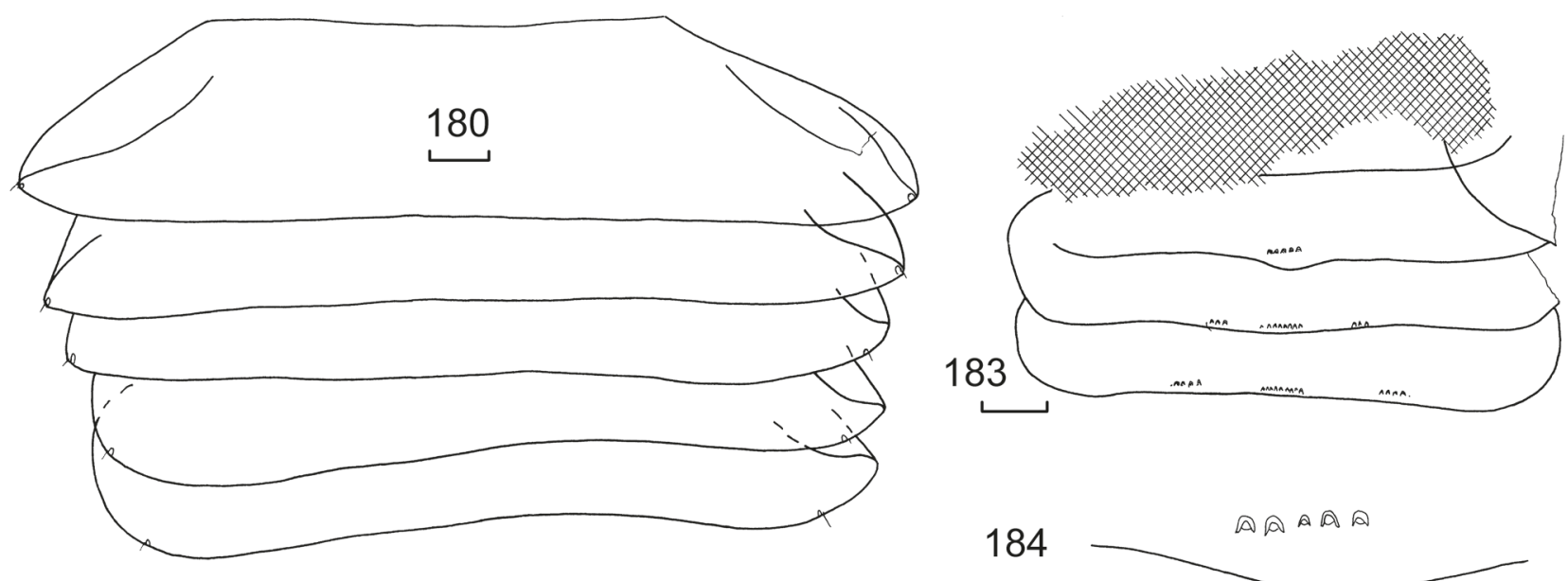

184
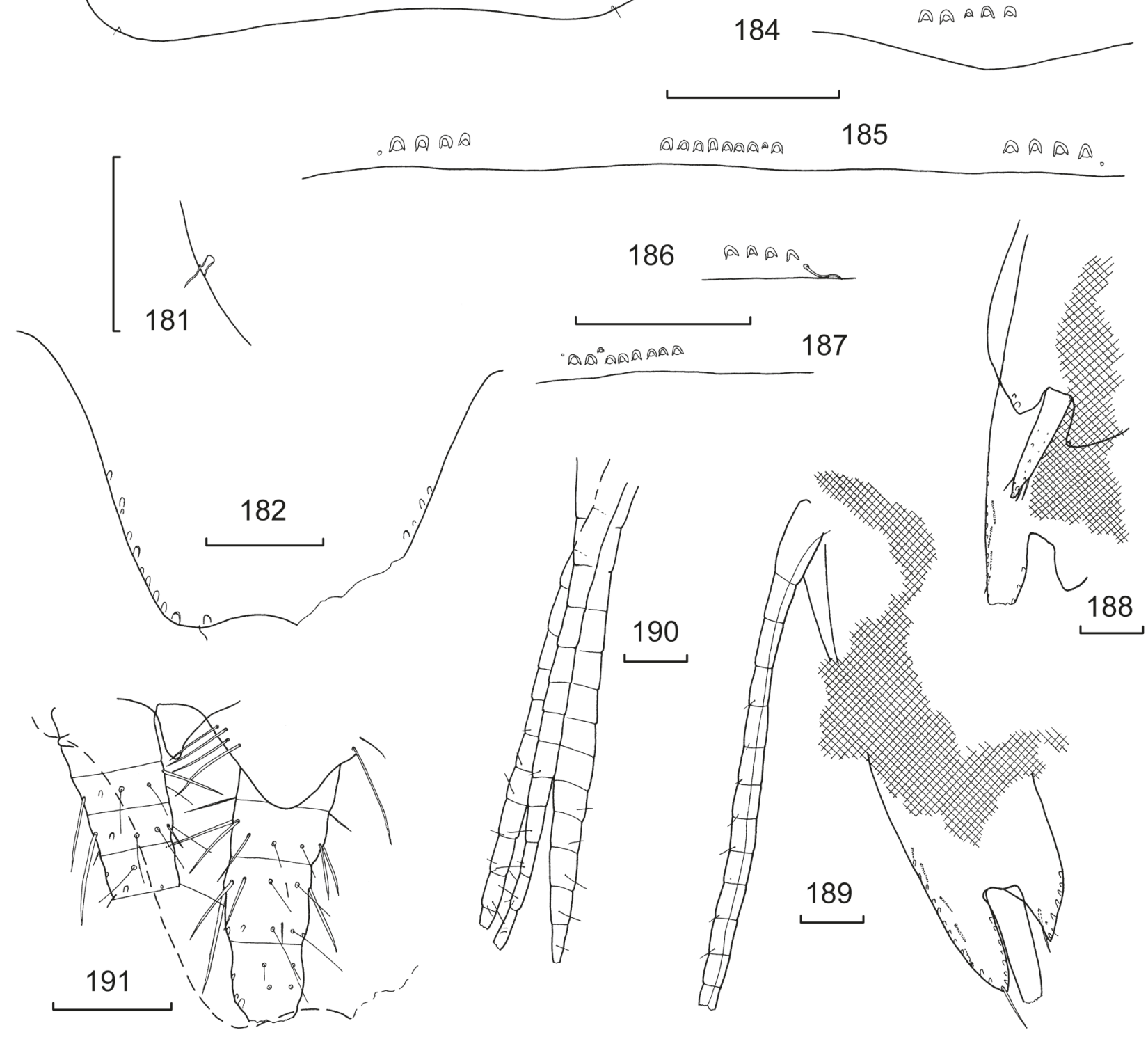

FIGURES 180-191 Xenolepisma perexiguum sp. nov., holotype female (WAM E89224): 180, urotergites I-V; 181, insertion point left lateral macrochaeta of urotergite $V_{;}$182, urotergite $X$, damaged in right posterior corner; 183, urosternites I-IV, cross hatched area obscured by tissue; 184, posterior margin of urosternite II; 185 , posterior margin of urosternite IV; 186, left lateral comb of urosternite $\mathrm{V} ; 187$, medial comb of urosternite V; 188, urosternite VIII, cross-hatched areas obscured by tissue; 189, urosternite IX and valve of ovipositor, apex of stylet and ovipositor damaged; 190, ovipositor, remaining valves; 191, remaining divisions of cerci and median dorsal appendage, with outline of urotergite X. PII. All scale bars $=0.1 \mathrm{~mm}$. 
TABLE 4 Number of macrochaetae per bristlecomb Xenolepisma perexiguum sp. nov.

\begin{tabular}{ll|ll} 
& Urotergites & Urosternites \\
& $\begin{array}{l}\text { Isolated } \\
\text { macrochaetae } \\
\text { per side }\end{array}$ & $\begin{array}{l}\text { Macrochaetae } \\
\text { per comb }\end{array}$ \\
Segment & $\begin{array}{l}\text { (including infralaterals) } \\
\text { Sublateral }\end{array}$ & Medial \\
\hline I & $1+1$ & - & - \\
II & $1+1$ & - & 5 \\
III & $1+1$ & 3 & 8 \\
IV & $1+1$ & 4 & 9 \\
V & $1+1$ & $4-5$ & 9 \\
VI & $1+1$ & $4-5$ & 9 \\
VII & $1+1$ & 4 & 6 \\
VIII & $1+1$ & 2 & - \\
IX & $1+1$ & - & - \\
\hline
\end{tabular}

with one or two of the setae much smaller (judging by the size of the insertions) and offset from the line of the comb anteriorly, rarely associated with a cilium (only seen once on VII). The sublateral combs on III more mediad than those of the more posterior segments and the posterior margin of VII somewhat more concave than the rest.

Coxites VIII of female with not well preserved, appear to be without combs but with two setae on one of the processes (internal?) (Figure 188). Internal process of coxite IX of female (Figure 189) about twice as long as broad at the base and 1.4 times as long as the external process. Stylets on urosternites VIII and IX in female holotype, although damaged on coxite IX (Figures 188, 189). Ovipositor (Figures 189, 190) with apex missing, surviving portion just reaching to end of apex of coxites IX, with 13 divisions remaining and only one to three short, fine setae per division in the more distal divisions.

Terminal filaments damaged but probably not extending much beyond the end of urotergite $\mathrm{X}$, only four divisions of both cerci and median filament preserved; both appendages with setae and trichobothria as in figure 191.

Male: Unknown.

\section{ETYMOLOGY}

The species is named from the Latin adjective perexiguus meaning very small or very short, referring to its minute size.

\section{HABITAT}

Only a single female specimen was found among the extensive Barrow Island material. It was taken in a pitfall trap near the old drill workshops, along with 23 other silverfish of the genus Acrotelsella. Ants of several species were also found in this pitfall trap and, given the strongly ateluriform shape of this species and the associations known for other species of Xenolepisma, it is probably associated with one of the smaller ant species.

\section{DISCUSSION}

This is fifth species to be described from the genus and the second to be described from Australia. A key to the described species of the genus Xenolepisma is given below.

1. Posterior margins of nota with submarginal row of isolated macrochaetae ....X. monteithi Smith, 2015

Posterior margins of nota glabrous (except for a single lateral macrochaeta in each posterolateral corner)

2. Posterior margins of urotergites I-VIII glabrous (except for $1+1$ single infralateral macrochaetae) $X$. perexiguum sp. nov.

Posterior margins of urotergites with $3+3$ or $5+5$ isolated submarginal dorsal macrochaetae ......... 3

3. Posterior margins of urotergites I-VIII provided with 5+5 macrochaetae. Median comb of urosternites with 4-5 and the laterals with 2-4 setae, the distance separating them 3-4 times greater than the width of the latter. Parameres very small, provided with about six thin setae. Internal process of coxite IX of the male a bit longer than wide at its base

X. subnigrina (Silvestri, 1938)

Posterior margins of urotergites II-VIII with $3+3$ macrochaetae. Internal process of coxites IX of male more than 1.5 times longer than wide at base

4. Medial comb of urosternites with 6-10 macrochaetae, the sublateral combs with four setae, the distance that separates them 2-2.5 times the width of the former. Pigment intense on the vertex of head, appendages and part of body. Parameres reduced, devoid of chaetotaxy X. globosa (Escherich, 1905)

Median comb of urosternites with 3-5 long, thin macrochaetae, the sublateral combs with 2-4 macrochaetae, the distance separating them more than four times the width of the former. Pigment on head only intense on lateral and anterior margins. Parameres small with a few thin setae $X$. penangi Smith and Kuah, 2011 


\section{ACKNOWLEDGEMENTS}

I would like to thank Ms Sue Lindsay (Microscopy and Microanalysis Unit, Australian Museum, Sydney) for the electron micrographs, Dr Luis Mendes (Instituto de Investigação Científica Tropical (IICT), Lisbon, Portugal) for advice on the generic placement of the species, Dr Rafael Molero-Baltanás (University of Cordoba) for discussions on the nomenclature of antennal components and Professor Jonathon Majer, Dr Nihara Gunawardene, Dr Shae Callan and the Curtin University team for the supply of the material.

\section{REFERENCES}

Adel, T. (1984). Sensilleninventar und sensillenmuster auf den Antennen von Thermobia domestica und Lepisma saccharina (Insecta: Zygentoma). Braunschweiger Naturkundliche Schriften 2: 191-217.

Burmeister, H. (1838). Handbuch der Entomologie. T. II, Abt. II, H. 1, Berlin, 360pp.

Callan, S.K., Majer, J.D., Edwards, K. and Moro, D. (2011). Documenting the terrestrial invertebrate fauna of Barrow Island, Western Australia. Australian Journal of Entomology 50(4): 323-343.

Larink, O. (1986). Pattern of antennal sensilla in some Lepismatidae (Insecta: Zygentoma). Pp 237-241 in Dallai, R. (ed) $2^{\text {nd }}$ International Seminar on Apterygota: Universiti of Siena, Siena.

Latreille, P.A. (1802). Histoire Naturelle, générale et particulière des Crustacés et des Insectes. 3, Dufart, Paris, France, 468 pp.
Mendes, L.F. (1981). Nota sobre o género Asterolepisma e descrição de una nova especie (Zygentoma, Lepsimatidae). Revue de Zoologie Africaine (Tervuren) 95(1): 200-209.

Mendes, L.F. (1991). 1.1. On the phylogeny of the genera of Lepismatidae (Insecta: Zygentoma). pp. 3-13 in Veeresh, G.K., Rajagopal, D. \& Viraktamath, C.A. (eds) Advances in management and conservation of soil fauna. Oxford \& IBH Publishing Co. Pvt. Ltd., New Delhi Bombay Calcutta.

Mendes, L.F. (2012). On a new species of Heterolepisma Escherich, 1905 from Melanesia (Insecta: Zygentoma). Boletín de la Sociedad Entomológica Aragonesa (S.E.A.), 50: 149-152.

Molero-Baltanás, R., Gaju-Ricart, M. \& Bach de Roca, C. (2000). On the taxonomic use of the distribution pattern of the antennal asteriform sensilla in Neoasterolepisma and Tricholepisma (Insecta, Zygentoma, Lepismatidae). Pedobiologia 44: 248-256.

Silvestri, F. (1935). Marquesan Thysanura. Bulletin of the Bernice Pauahi Bishop Museum 114: 305-312.

Smith, G.B. (2013): A new species of Heterolepisma from Barrow Island (Zygentoma: Lepismatidae). Records of the Western Australian Museum. Supplement 83: 229-240.

Smith, G.B. (2015). New silverfish taxa from Queensland (Zygentoma: Lepismatidae). Records of the Australian Museum 67: 67-81.

Stach, J. (1932). III. Die Apterygoten aus den Galapagos-Inseln. Meddelelser fra det Zoologiske Museum Oslo 29: 331-346, tabs II-IV.

MANUSCRIPT RECEIVED 27 JUNE 2015; ACCEPTED 23 SEPTEMBER 2015. 